Andrea Consiglio' / Stavros A. Zenios ${ }^{2,3,4}$

\title{
Contingent Convertible Bonds for Sovereign Debt Risk Management
}

\author{
${ }^{1}$ University of Palermo, Palermo, Italy \\ 2 University of Cyprus, Nicosia, Cyprus, E-mail: zenios.stavros@ucy.ac.cy \\ ${ }^{3}$ The Wharton Financial Institutions Center, University of Pennsylvania, PA, USA, E-mail: zenios.stavros@ucy.ac.cy \\ ${ }^{4}$ Non-Resident Fellow, Bruegel, Brussels, Belgium, E-mail: zenios.stavros@ucy.ac.cy
}

\begin{abstract}
:
We consider convertible bonds that contractually stipulate payment standstill, contingent on a market indicator of a sovereign's credit worthiness breaching a distress threshold. This financial innovation limits ex ante the likelihood of debt crises and imposes ex post risk sharing between creditors and the debtor. Drawing from literature on contingent contracts, neglected risks, and bank $\mathrm{CoCo}$, we extend prevailing arguments in favor of sovereign $\mathrm{CoCo}(\mathrm{S}-\mathrm{CoCo})$. We discuss issues relating to their design: which market trigger, market discipline and sovereign incentives, and errors of false alarms or missed crises, and provide supporting evidence with eurozone data and a simple simulation on the use of S-CoCo. We develop a risk management model using these instruments to trade off the expected cost for sovereign financing over a long horizon, with tail risk. The model shows how contingent bonds can improve a country's debt risk profile. Using Greece as a case study the model illustrates improvements in expected cost vs. tail risk for the country when using contingent debt.
\end{abstract}

Keywords: conditional Value-at-Risk, contingent contracts, debt crisis, debt restructuring, GDP-indexed bonds, portfolio optimization, puttable bonds, scenario analysis, sovereign debt

DOI: $10.1515 /$ jgd-2017-0011

\section{Introduction}

Contingent debt for sovereigns has been receiving increasing attention following the decision of G20 finance ministers and central bank governors in July 2016, to call on International Monetary Fund to analyze "technicalities, opportunities, and challenges of state-contingent debt instruments." ${ }^{1}$ One class of instruments stipulates payment standstill and extension of maturities, contingent on some adverse effect relating to the sovereign's ability to service its debt. Proposals for such instruments were made, independently, by Weber, Ulbrich, and Wendorff (2011), Barkbu, Eichengreen, and Mody (2012), Brooke et al. (2013), and Buiter and Silbert (1999). IMF submitted its report to the G20 in May 2017 (IMF 2017).

We make two contributions. First, we propose a concrete market-based trigger, and illustrate with eurozone data and a simple simulation how such instruments could have worked during the eurozone crisis. We also draw from literature on contingent contracts, neglected risks, and bank CoCo to extend prevailing arguments in favor of sovereign contingent debt, thus adding to the qualitative discussions that preceded ours. Second, we develop a risk management model to incorporate contingent debt in sovereign financing decisions, and illustrates improvements in the sovereign's debt risk profile, calibrating and testing the model using Greece as a case study. To the best of our knowledge, this is the first quantitative contribution to the debate on this type of instruments, together with a model developed more recently in (IMF 2017, Annex).

The class of instruments we consider is defined as follows:

Sovereign contingent convertible debt (S-CoCo). A sovereign debt instrument with a built-in trigger to allow payment standstill for a grace period when an indicator breaches a threshold.

A major question is what triggers a standstill, and we argue for a market based trigger, such as credit default swap (CDS) spreads, activated when a distress threshold is breached. There is also an important issue on how to distinguish between a liquidity crisis, that can be effectively addressed by the standstill, and insolvency risk that a standstill will not solve, and the role of a regulator in moderating the automatic trigger (Hart and Zingales 2011). We first study the financial instrument, and then discuss the role of the official sector, such as the European Stability Mechanism in the eurozone. 
This proposal responds to the evidence of persistent problems with sovereign debt. Debt crises are rare but they have been increasing both in frequency and in magnitude. From a Bank of Canada database on sovereign debt default world-wide (Beers and Nadeau 2015), we find that up to $55 \%$ of the world sovereigns had been in default at some point since 1975 on hundreds of billions USD, although the total debt in default averages only $1.8 \%$ of global sovereign debt. The number and size of IMF programs keeps increasing. The average program during 1992-2012 was about 3\% of the recipient's GDP for 1.5 years, the programs for Latin American crisis countries were $6 \%$ of GDP for 3 years, and for the Eurozone crisis up to 18\% GDP for an average of 4 years (Pisani-Ferry, Sapir, and Wolff 2013). Figure 1 highlights the persistence of problems, quite forcefully, for a sample of countries from the database of Trebesch (2011), for both sovereign (Paris club) and bank debt restructuring. We note especially the prevalence of serial defaults. Even "advanced countries have relied far more on [methods that include debt restructuring] than many observers choose to remember," note Reinhart, Reinhart, and Rogoff (2015).

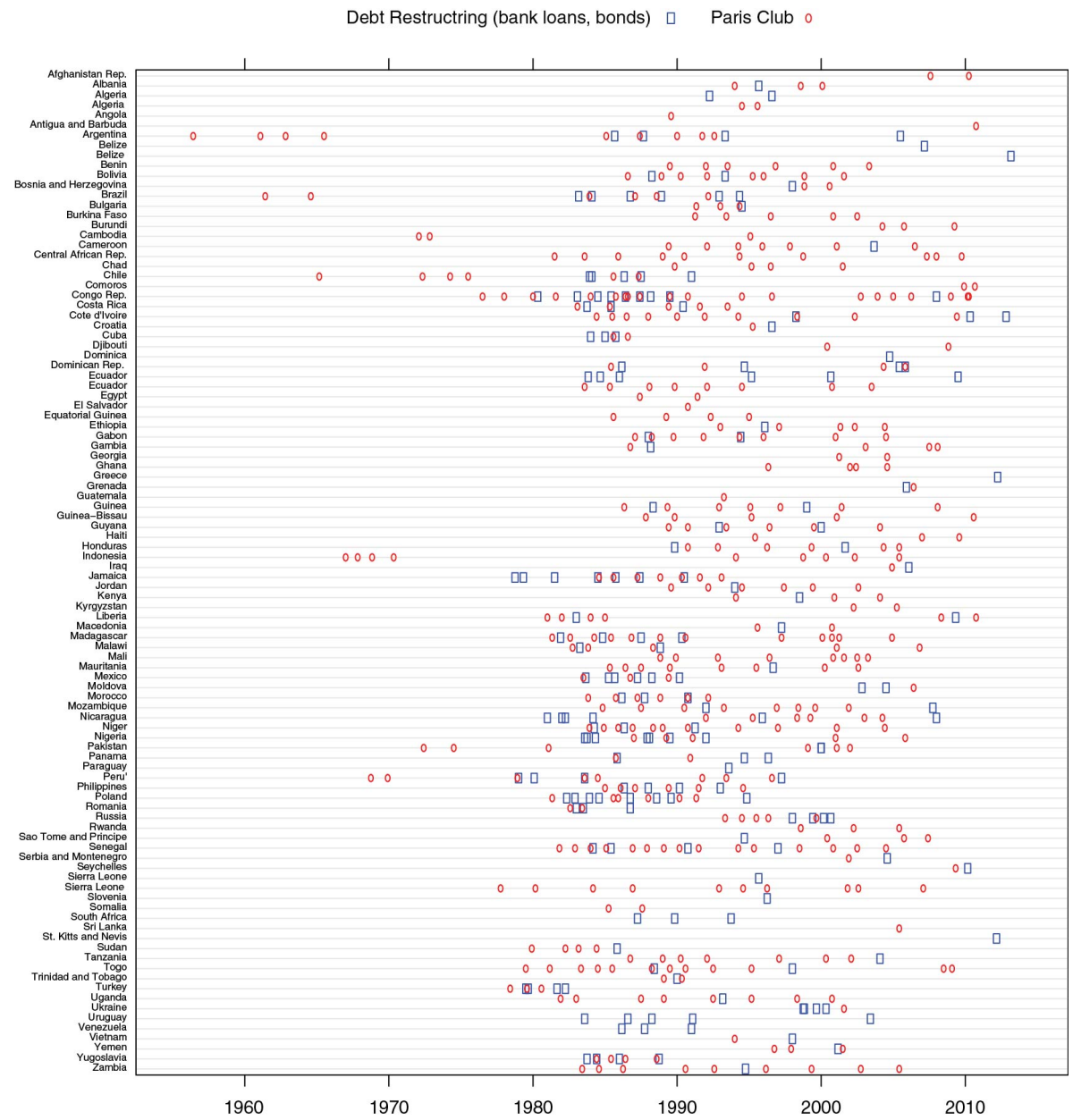

Figure 1: Serial defaults: 60 years of foreign sovereign debt restructuring for a sample of countries. Data: from the database of Trebesch (2011).

Instruments that contractually specify debt rescheduling under adverse conditions can bring welfare benefits without triggering sanctions. The desideratum is debt relief that restores sustainability (Guzman and Lombardi 2018). The proposal we make here, and consistently with (Buiter and Silbert 1999; Weber, Ulbrich, and Wendorff 2011; Barkbu, Eichengreen, and Mody 2012; Brooke et al. 2013; IMF 2017), is not for debt relief per se, but for a temporary payment standstill. Thus S-CoCo address a sovereign's liquidity problems but not solvency problems, although dealing with liquidity problems alleviates the risk of liquidity turning into insolvency crisis.

The debate on the benefits of debt relief is ongoing (Reinhart and Trebesch 2016). Some contributions argue about welfare benefits of forgiving debt in situations of debt overhang, with both creditors and debtors gaining from a partial debt-write-down, while others argue that restructuring can cause reputational damage and trigger sanctions and output losses. The literature on the cost of delays and the ongoing debate on the penalties from insufficient relief is extensive, see, e.g. (Consiglio and Zenios 2016, pp. 187-188). Nevertheless, there is a consensus that given the ex post inefficiencies associated with the lack of a system for discharge of sovereigns' unsustainable debt burdens, there is value in decreasing the ex ante probability of default, and S-CoCo could 
contribute towards this goal. The cost of delaying the restructuring of destabilizing debt burdens is well documented in the theoretical literature, see, e.g. Guzman and Stiglitz (2016) and Krugman (1988). Several empirical studies document various deficiencies in the sovereign debt restructuring processes. For instance, Benjamin and Wright (2009) found that average default takes almost 8 years to resolve and leaves the sovereign country more highly indebted than when it entered default, Schumacher, Trebesch, and Enderlein (2018) discuss the problem of increasing litigation against sovereign debtors, and Guzman and Lombardi (2018) show that 49-60\% of the sovereign debt restructuring episodes since 1970 have been followed by another default or restructuring within 3-7 years, suggesting the existence of "too little" relief in sovereign debt restructuring processes which would explain serial defaults.

S-CoCo provide a financial innovation response to sovereign debt crises through the ex ante introduction of distress contingencies into debt contracts. A payment standstill limits debt repayment thus potentially avoiding default with its adverse effects. The proposed instrument does not eliminate litigation altogether, especially if a liquidity crisis turns into an insolvency crisis, but specific distress situations are covered by the contract and the sovereign and the creditors are given time during the payment standstill, to deal with the problem.

Maturity extension contingent debt was used for some African countries in 2009 by the French Aid Agency (AFD) (Brooke et al. 2013). Ex post maturity extension is not uncommon, and well-known instances are 1997 Korea, 2000 Turkey and the Vienna Initiative for ex-Soviet Union european countries. Our contribution is to incorporate ex ante maturity extensions in a contingent contract.

We draw on ideas of convertible debt for banks (B-CoCo), noting that S-CoCo are quite different. B-CoCo convert debt to equity with a complete write-down of equity, whereas S-CoCo convert to debt with more favorable repayment schedule. Contingent debt for banks was suggested by Flannery $(2005,2014)$, who argued that they bring market discipline to the recapitalization of large banks under stress. However, criticisms have been voiced. Bond, Goldstein, and Prescott (2010) discuss difficulties in using market data to signal contingencies when the signal provokes policy responses priced by the market, and Sundaresan and Wang (2015) raise the possibility of multiple equilibria. Successful deployment of these instruments hinges on overcoming the shortcomings pointed by their critics, and suggestions have been made by Hart and Zingales (2011), Calomiris and Herring (2013), McDonald (2013), and Avdjeiv et al. (2015). We use, in particular, the contribution of HartZingales who assign a role to the regulator when B-CoCo are converted, and we assign a role to the European Stability Mechanism in implementing S-CoCo in the eurozone. Notwithstanding the criticism, Basel III allows banks to meet regulatory capital requirements with CoCo instruments, and the market is rapidly growing. Avdjeiv, Kartasheva, and Bogdanova (2013) report \$70bn for banks between 2009 and 2013, issuance increased significantly in 2014, with 187 instruments for $\$ 208$ bn by 68 banks (Avdjeiv et al. 2015), and by 2016 the market reached 730 instruments totalling $\$ 521$ bn (Avdjiev et al. 2017).

Contingent capital is used by insurance and re-insurance firms to supplement reserves for protection against catastrophic events, in manufacturing as source of capital during downturns of the business cycle, by rated firms as part of capital management to satisfy rating agencies, and as supplementary liability insurance by service firms (Culp 2002).

Our paper adds to earlier contributions by suggesting and analyzing a fully specified type of contingent debt. In Sections 2 and 3 we justify the use of sovereign state-contingent convertible debt and discuss issues relating to their design: which market trigger, market discipline and sovereign incentives, and errors of false alarms or missed crises. The discussion is supported using eurozone data and a simple simulation on the use of S-CoCo. Section 4 discusses challenges in introducing these products, and the role of the official sector, such as the European Stability Mechanism, in promoting and incentivising these instruments in the eurozone. Section 5 develops the risk management model and uses Greece as a case study to show, in Section 6, improvements in the risk profile of the country's debt. Section 7 concludes.

\section{Why Contingent Debt for Sovereigns}

Sovereign contingent debt makes distress (i.e. "near default") contingencies part of the legal contract, and the ensuing payment standstill can help the sovereign avoid immediate default. Two arguments from the literature on contingent contracts (Bazerman and Gillespie 1999) support making default contingency part of a sovereign debt contract. First, it imposes risk sharing between debtor and creditors. The debtor pays a premium to the creditors for the benefit of a potential standstill, whereas the creditors suffer losses form a standstill. This risk sharing solves creditor moral hazard, as we discuss later. Second, it forces the debtor and its creditors to avoid biases. Without the contingent standstill, the sovereign has a biased over-confidence that their debts can be fully repaid and there will not be any default. And if (when) its ill-placed confidence is proven unfounded, it "gambles for redemption" (Conesa and Kehoe 2015). With the contingent contract the debtor pays a premium 
for potentially breaching a well-defined threshold and this adverse non-default event is not ignored in the same way that default is ignored as an eventuality. The creditors' blind spot is in providing credit expecting full repayment. For instance, Cyprus banks exhibited blind spots in carry trade of Greek government bonds with ECB financing (Acharya and Steffen 2015) on the working hypothesis that "there will be no stop of payments for the public debt of a eurozone country" (Zenios 2016). Eventually almost 25\% of Cyprus GDP was lost with the Greek private sector involvement (PSI) with nominal value haircuts. Instead of being over-confident on their views, debtor and creditors make the contingency part of the contract.

Avoiding biases points to recent literature on neglected risks (Gennaioli, Shleifer, and Vishny 2012) which provides an alternative justification for S-CoCo. They argue that investors neglect certain unlikely risks, financial intermediaries provide securities exposed to these neglected risks, and because the risks are neglected security issuance is excessive. When (if) these neglected risks are realized investors flee and markets become fragile, even without leverage, precisely because the volume of new claims is excessive. Mody (2013) uses this argument in explaining the eurozone crisis. Sovereign debt was regarded as risk-free, a notion fostered by zero risk weighting of sovereign assets held by banks, and euro area banks had excessive sovereign exposure. The Deauville agreement between Chancellor Merkel and President Sarkozy on 19 October 2010, put on the table the neglected risk of sovereign debt restructuring, resulting in sovereign distress and escalating into financial panic. With the use of S-CoCo, neglected risks are not neglected any more. The adverse states of the world in the S-CoCo is the breaching of a well-defined indicator that is explicit in the contract, and for which we have continuous market information. Sovereign CoCo may still suffer from overpricing in good times and underpricing in bad times, but a larger share of risks have been made explicit and transparent through the indicator. Risks are less likely to be neglected. On the contrary, the default event can be neglected for two reasons. First, it must be avoided since there is no sovereign bankruptcy procedure. Second, there is an expectation of bail-out. Therefore, the standstill risk is priced even if the extreme default event may be neglected.

The literature on contingent contracts and neglected risks is distinct, and the authors did not make a connection between the two. The contingent contract literature explains how biases can be avoided. (Gennaioli, Shleifer, and Vishny 2012) call specific biases "neglected risks," and model the macro effects of this specific biases of the contracting parties on the fragility of the markets. The former literature gives a micro justification for $\mathrm{S}-\mathrm{CoCo}$, from the point of view of the contracting parties. The latter gives the macro justification, from the point of view of financial market stability.

\subsection{Goals of Sovereign Contingent Debt}

We now discuss the implications for S-CoCo. Literature on contingent debt for banks (Flannery 2014) provides some guidance, although it does not apply mutadis mutandis to sovereigns. In B-CoCo, conversion is from debt to equity, whereas in S-CoCo conversion is from one type of debt to another with favorable repayment schedule. Some of the arguments we provide here have been made in Barkbu, Eichengreen, and Mody (2012), Brooke et al. (2013), and IMF (2017), and some are new.

Automatic stabilisers. Once a country enters a crisis zone, fiscal solvency requires a combination of concessional financing and austerity to create primary surplus and reduce public debt. As several authors pointed out, during the eurozone crisis this strategy left very limited scope for countercyclical fiscal support. A standstill on debt payment lowers primary surplus needs and creates space for fiscal intervention. The automatic stabilisation makes default less likely by avoiding liquidity crises turning into solvency crises. Similarly, the official sector does not need to pay out existing bond holders, and more money is available for a gradual and less costly economic adjustment path. For instance, privatisation of state-owned-enterprises, used by countries in crisis to pay down debts, does not need to take place under fire-sales conditions that generate less income and may have a detrimental effect on macro-financial stability, since standstill gives more time for privatisation plans. Avoiding fire sales is one of the arguments for B-CoCo (Flannery 2014).

Reinhart, Rogoff, and Savastano (2003) attribute the inability of debt intolerant countries to stay within safe debt levels to, among other reasons, the pro-cyclical nature of capital markets that lend in boom times only to retrench when there is a shock. The standstill provides an automatic stabiliser to finicky market behaviour. If inflows stop so does the outflow for debt payments. This important point was recognised for GDP-linked bonds (Brooke et al. 2013) but not for S-CoCo.

Forestalling default during a crisis. The payment standstill gives the sovereign a grace period to correct public finance imbalances. While the S-CoCo does not address insolvency situations, it addresses liquidity crises. Brooke et al. (2013) argue that the standstill gives space so that a liquidity crisis does not evolve into an insolvency situation. In B-CoCo the goal is to forestall default during systemic crises but allow institutions to fail for idiosyncratic problems. This is achieved through a dual trigger (McDonald 2013), one institutionspecific (e.g. stock price), and another market-specific (e.g. a financial institutions index). This structure protects financial firms during systemic crises, but lets them go bankrupt if they perform badly during normal times, 
and these failures are healthy for market efficiency. However, sovereigns do not fail and the standstill should be triggered by a unique idiosyncratic indicator.

Market discipline for debtors. What are the incentives for the debtor not to provoke the standstill? The answer is found, in part, in market discipline. One reason why sovereigns get into debt crises is the fact that benefits from borrowing come immediately, whereas the risk of default is borne in the future. This encourages governments with short horizon towards excessive debt. S-CoCo price ex ante the risk of future payment standstills thus making the costs immediately visible. With risk sharing between creditors and debtor, the interest charged on S-CoCo will increase as a crisis zone is approached, and this will be an early warning signal for standard bonds as well, disciplining the sovereign. For Brooke et al. (2013), market discipline is the primary goal of contingent debt.

With simple bonds, markets also give disciplining warnings with yield increases. However, warnings from S-CoCo lead warnings from straight bonds as standstill precedes defaults and there is evidence that CDS markets lead in price discovery (Blanco, Brennan, and Marsh 2005). Hence, contingent debt does not encourage more risk taking than current instruments, and the discipline by the market is in the right direction. This issue is discussed for banks by Calomiris and Kahn (1991) and (McDonald 2013, p. 233).

Creditor moral hazard. Brooke et al. (2013) make a distinction between creditor and debtor moral hazard, and S-CoCo address the former.

First, we have the propensity of creditors to buy short term debt from crisis countries. This is based on the assumption that, in the short term, a country in crisis is likely to pay its debts due to an international official assistance program, but the long term prospects are unclear. In the short-run the country is treated as having a liquidity problem that will be solved with official sector assistance, but in the long-term the country may be facing an insolvency problem that requires private creditors to contribute. S-CoCo embeds the uncertainty about liquidity vs insolvency in the contract. Short-term creditors could see the standstill triggered the same way that long-term creditors may witness a default. Hence, flight to short term debt, with its adverse effect on long-term yields, is arrested.

Second, we have the burden on taxpayers from sovereign bail-out. The standstill reduces the size of an assistance program and creditors can not count on the official sector to carry all costs. This point is emphasized in Weber, Ulbrich, and Wendorff (2011) and Brooke et al. (2013).

Speedy response to crises. While sovereign CoCos can not resolve insolvency crises, they reduce the cost of debt restructuring. When defaults occur it takes on average almost 8 years to resolve, and this delay destroys value for both creditors and debtor. Buchheit (2011) explains that failure to contain debt repayment to manageable levels imposes large costs by further undermining repayment capacity and distributing the burden in an arbitrary manner. Panizza (2013) reaches similar conclusions, makes a suggestion for the role of an international lender of last resort, and suggests that "contingent instruments would be an even better solution." In the same vein, the International Capital Markets Association suggests reforms in sovereign debt contracts (Gelpern, Heller, and Setser 2016).

Flannery (2014) emphasizes that B-CoCo replace supervisory discretion with rules, thus avoiding problems of regulatory forbearance that, for many reasons, play a significant role in banking crises. The equivalent malaise in sovereign crises is the "pathological procrastination" (Buchheit 2011) exhibited both by sovereigns in trouble and the international organizations that come to the rescue (Rhodes and Stelter 2011). S-CoCo force creditors and debtor to act as soon an objective criterion is satisfied, and this was one of the major motivations for Weber, Ulbrich, and Wendorff (2011) and Mody (2013) in making their proposals. Hart and Zingales (2011) argue, however, that there is a need for a regulator to mediate the automatic trigger, and we adopt their argument to assign a role to the official sector later on. The trigger forces the regulator or the official sector to act rapidly, however things are not totally automatic.

The above arguments point to improved financial stability if S-CoCo are part of the sovereign debt financing options. However, these instruments are not without potential pitfalls and there are challenges in their practical adoption. We defer a discussion of the challenges to the next section, after we specify further the design.

\subsection{Some Other Proposals}

Other proposals for sovereign contingent debt instruments to achieve some (combination) of the above goals include GDP-linked bonds (Borensztein et al. 2004; Kamstra and Shiller 2009) or, more recently and less discussed, puttable bonds (Neftci and Santos 2003; Bögli and Fattinger 2015). These proposals are quite distinct from S-CoCo and we highlight the differences. This is not meant as a comprehensive comparison, see Brooke et al. (2013) and IMF (2017) for comparisons of GDP-linked bonds and S-CoCo. Emphasizing the differences and highlighting some of the problems, is not to claim that they fail to achieve some of the goals required of contingent debt. 
A complementary contingent debt product are GDP-linked bonds (Borensztein et al. 2004) but S-CoCos are quite distinct. The fundamental distinction is that GDP-linked bonds are equity-like, and investors buy a stake in the country's economy. S-CoCo is debt, and only under conditions of sovereign stress the buyer has a stake in the country's economy, and even then the risks are well defined and limited. A comparison of S-CoCo with GDP-linked bond as insurance instruments for euro-zone countries is discussed in Demertzis and Zenios (2018).

Puttable bonds allow investors to return the bond to the sovereign at a predetermined price, thereby reducing investor risk and lowering sovereign borrowing interest. However, when a crisis develops the sovereign is not in a position to honor the put option which must be guaranteed by an intergovernmental organization, such as the European Stability Mechanism. Hence, risks are transferred (for a price, of course) from the sovereign and its creditors to the official sector, whereas S-CoCo aim at risk sharing between creditors and the sovereign.

\section{Sovereign Contingent Debt Designs}

We now go into details of the design.

\subsection{Which Trigger(s)}

An appropriate trigger must be accurate, timely, and comprehensive in its valuation of the issuing entity (Calomiris and Kahn 1991), and should be defined so that it can be implemented in a predictable way. Barkbu, Eichengreen, and Mody (2012) suggest debt-to-GDP ratio as trigger and Brooke et al. (2013) left open the choice of trigger.

Market data indicating a sovereign's probability of default are CDS spreads. CDS spreads are timely and comprehensive as they aggregate the views of multiple market participants and incorporate information about a sovereign's contingent liabilities. Eurozone data illustrate how a CDS spread trigger would have provided early warning, see Figure 2 . We set the threshold at $500 \mathrm{bp}$, which corresponds to probability of default about $10 \%^{2}$, therefore default risks at the $10 \%$ confidence level are not neglected. We use a 30-day moving average as the trigger. Table 1 shows the timing of potential standstills in the eurozone, together with the date of signing an international assistance program for crisis countries, and the average annual saving from the 3-year grace period as a proportion of the country's GDP.

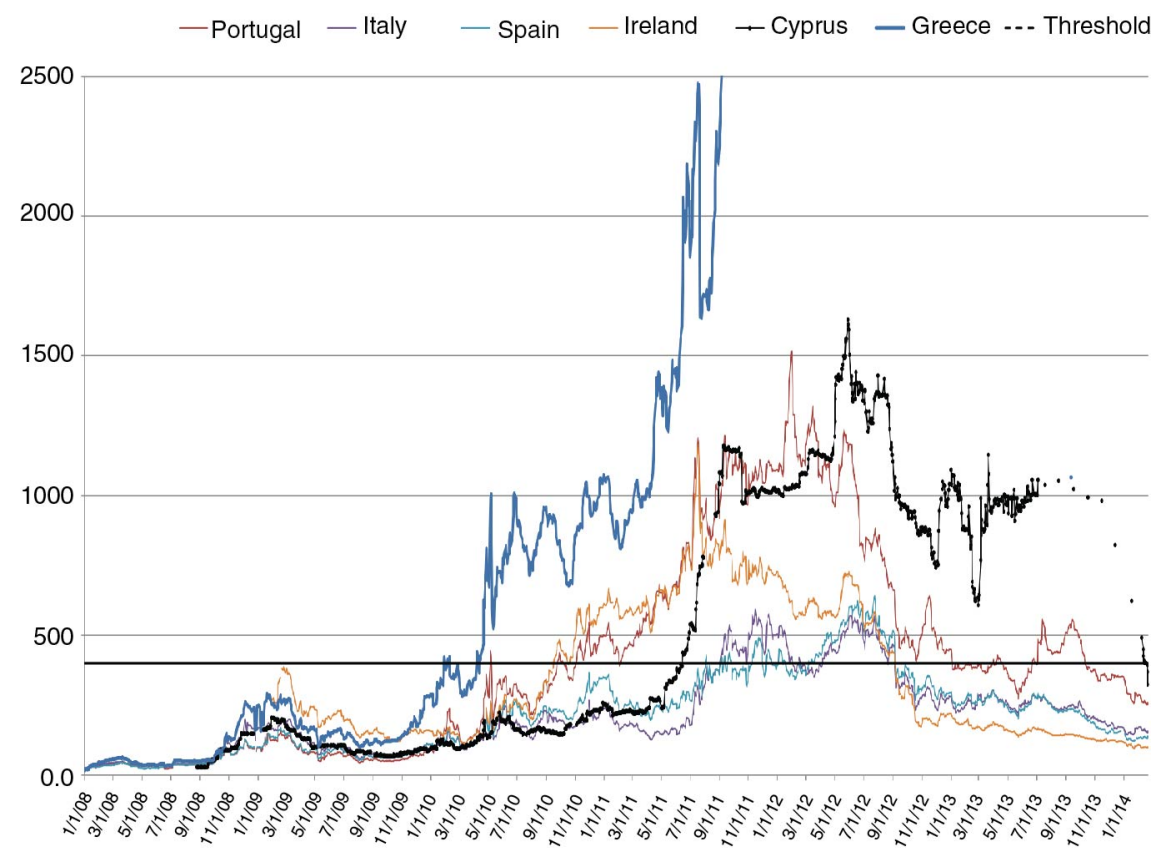

Figure 2: The 5-year CDS spread on eurozone crisis countries and the trigger threshold. Data: Datastream and authors' calculations.

We observe that for Greece, Spain, and Cyprus several months passed from an S-CoCo warning to the signing of an agreement. With S-CoCo the response would have been swift. Greece would have received relief through payment standstill during the first semester of 2010 and not with the PSI haircut at the end of 2011, that 
was "too little and too late" according to IMF. (Although, as we will see later, a 3-year standstill would not have been sufficient) Cyprus was an extreme case of government procrastination that created a "perfect crisis" and resulted in depositor bail-in (Zenios 2016). Portugal and Ireland responded swiftly and signed an agreement within a couple of months.

A threshold at 500bp seems to be giving false alarms for Bulgaria, Italy, and Lithuania, but no eurozone crisis country was missed. Bulgaria had various facilities extended by the IMF and the World Bank, including a standby arrangement approved in August 2004 and extended until March 2007, so Bulgaria's CDS already reflect international assistance. Lithuania contemplated asking for IMF assistance, but in the end managed on its own and did not follow in the footsteps of its neighbouring Baltic countries An Italian standstill would have been triggered during the last days of Silvio Berlusconi as Prime Minister, but the succession by Mario Monti and the measures taken by the new government pushed CDS spread below the threshold and Italy also managed the crisis on its own. ${ }^{3}$ We revisit false alarms and missed crises later.

Table 1: Date of example S-CoCo trigger with a threshold 500bp for eurozone crisis countries, with the associated savings from the standstill and early warning before signing an agreement with the IMF (ESM for Spain).

\begin{tabular}{llllr}
\hline Country & $\begin{array}{l}\text { Standstill } \\
\text { (triggered semester) }\end{array}$ & $\begin{array}{l}\text { Program } \\
\text { (start date) }\end{array}$ & $\begin{array}{l}\text { Early response } \\
\text { (months) }\end{array}$ & $\begin{array}{r}\text { Average savings } \\
\text { (\%GDP) }\end{array}$ \\
\hline Bulgaria & $2008 \mathrm{~S} 2$ & NA & NA & $0.44 \%$ \\
Ireland & $2010 S 2$ & 16 Dec. 2010 & 2.5 & $2.50 \%$ \\
Greece & $2010 S 1$ & 5 Sept. 2010 & 4 & $4.10 \%$ \\
Spain & $2012 S 1$ & Dec. 2012 & 12 & $2.48 \%$ \\
Italy & $2011 S 2$ & NA & NA & $4.47 \%$ \\
Cyprus & $2011 S 2$ & 15 May 2013 & 21 & $1.57 \%$ \\
Lithuania & $2009 S 1$ & NA & NA & $1.36 \%$ \\
Portugal & $2011 S 1$ & 20 May 2011 & 1.5 & $2.91 \%$ \\
\hline
\end{tabular}

${ }^{1}$ Based on the data of Figure 1, IMF program countries information, Bloomberg and authors' calculations.

\subsubsection{A Simple Simulation}

To illustrate how S-CoCo work, we carry out a simple simulation of the Greek economy over the period 20022017, Figure 3, using the simulator developed in Demertzis and Zenios (2018) to study S-CoCo and GDP-linked bonds as a type of sovereign insurance. We consider a payment standstill that starts at 2010S1, as calculated in Table 1, and for 3 years the country uses the average annual savings of $4.10 \%$ GDP for fiscal stimulus. The missed payments are repaid with interest over 10 years after the grace period, and we assume fiscal multiplier 0.6 during growth periods and 0.9 in recessions. Assuming that Greece could finance itself with S-CoCo issued at zero spread over the standard bonds (Figure 3A), then it would have benefited from the standstill during the peak of the crisis, the fiscal stimulus is significant, and the recession is much less deep (Figure 3B). In practice, Greece would have to pay a premium for issuing S-CoCo, and assuming a spread of $100 \mathrm{bp}$ in pricing the new instruments (Figure 3C) we get GDP that is moderated both in the upside and the downside (Figure 3D). Since the country has to repay the missed payment (with interest), the recovery slows down after the grace period.

This simple simulation highlights how the S-CoCo moderates the deep troughs of the economic cycle, but also the significance of the spread used to price the instrument. We turn our attention to the pricing of the new instruments. 
A
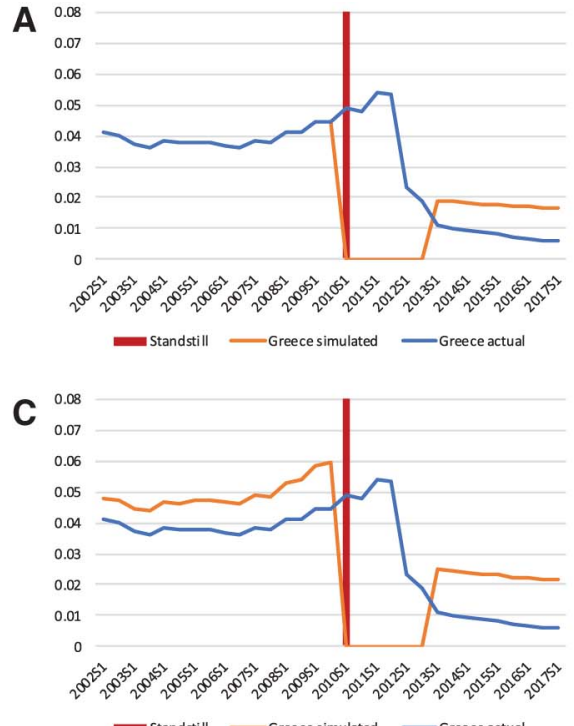

B 130000
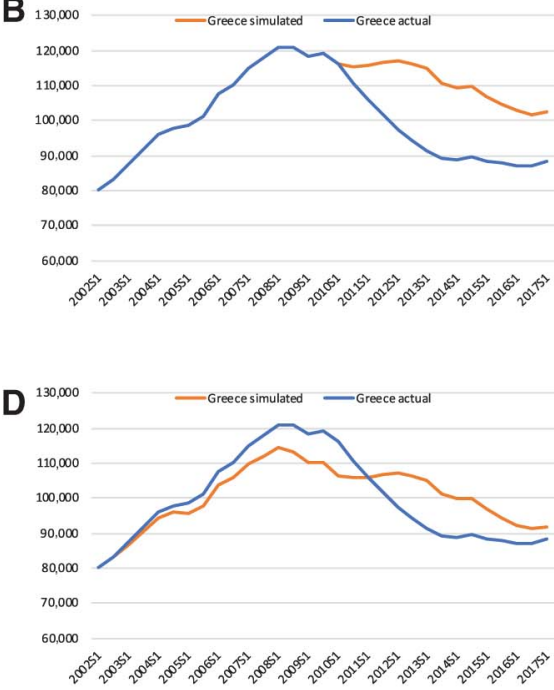

Figure 3: Greece interest payments and GDP growth simulated with the use of S-CoCo, and actual observed without SCoCo.

(a) Interest payment with S-CoCo price spread 0bp; (b) GDP growth with S-CoCo price spread 0bp; (c) Interest payment with S-CoCo price spread 100bp; (d) GDP growth with S-CoCo price spread 100bp. Source: Demertzis and Zenios (2018)

\subsection{Pricing and Incentives}

What are the incentives on a sovereign? Payment standstill is helpful - more money is left to finance government programs - and the sovereign may like to see it triggered. However, the pricing of S-CoCo creates disincentives. ${ }^{4}$

We price a 20-year S-CoCo with 3-year standstill triggered at different thresholds. To simulate the triggering CDS spread dynamics we fit to the log-returns of the spread an Orstein-Uhlenbeck process, as extended by O'Donoghue et al. (2014) to account for long-term mean reversion. The model ensures that spreads and their variance are bounded, non-negative, and exhibit the empirically-observed properties of stationarity and autocorrelations. The model is calibrated on Greece CDS spreads for the period 17 Dec. 2007 to 28 Feb. 2012. Bai-Perron regime switching identification is used to calibrate the model for different regimes during the crisis. The parameters of the extended Orstein-Uhlenbeck process are calibrated so that the process converges, in the long run, to the steady state estimates of the mean and standard deviation of CDS spreads, the standard deviation of spread returns, and to an estimate of the smoothness of spread returns, see Appendix A. The S-CoCo pricing model and details of the calibration are given in Consiglio, Tumminello, and Zenios (2016b).

We observe in Figure 4 a nonlinear increase of par yields for the S-CoCo as the threshold is lowered. The nonlinear increase is explained from the bell-shaped distribution of (30-day averaged) CDS spreads, since the number of scenarios exceeding a threshold increases nonlinearly with lower thresholds. The heavy tail further increases convexity. The increased financing rates of S-CoCo will be a signal with comparable effect on noncontingent debt. This is a disincentive to provoking a standstill. A sovereign that needs market access to finance its debt - or to pay salaries and pensions - can not trigger the standstill with impunity. The market charges a premium for the benefit of a potential standstill, and as the threshold is approached the spread increases nonlinearly with a commensurate increase of borrowing costs for the sovereign.

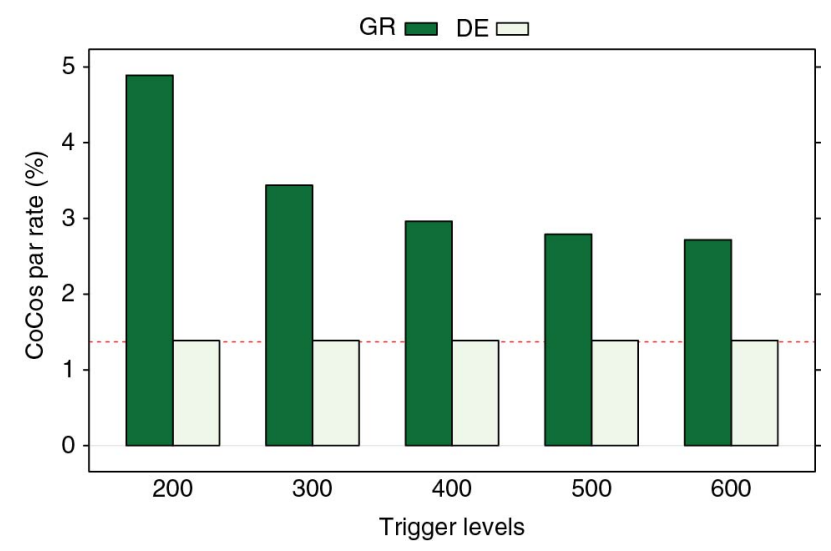


Figure 4: Par yields for S-CoCo increase non-linearly for lower thresholds. Greek 20-year S-CoCo trade at a discount as follows: 18\% for threshold 200, 15\% for 300, 13\% for 400 and $12 \%$ for 500 and 600. German S-CoCo trade at par with standard bonds, since the probability of CDS spread breaching even the 200 threshold is virtually zero. (Results with a 3-year grace period when the threshold is breached.) Source: Consiglio, Tumminello, and Zenios (2016b).

What about a sovereign running primary surplus? There is extensive literature explaining why sovereigns pay even if they have immunity, the main argument hinging on reputation risks from a default. This argument does not necessarily apply to contractually prescribed standstills. The instrument needs a design feature to deter sovereigns from triggering a standstill. One could think of pre-designed conditionality, such as earmarking tax revenues for resuming payments, or, for eurozone countries, budget approval by the Commission during a standstill. In Section 4 we assign a role to the European Stability Mechanism to alleviate this challenge. These options are unattractive for a sovereign, and a government that brings public finances to the point of activating a trigger dilutes its political capital, even as it may reap short-term economic benefits from a standstill. The government runs a risk of being voted out just like financial institutions remove the Board if B-CoCo is activated (Flannery 2014). Borensztein and Panizza (2009) report that governments in defaulting countries observed 16average decrease in electoral support, and for 18 out of 19 countries the ruling coalitions lost power.

\subsection{Grace Period}

The standstill can be a pre-specified grace period $\Delta \tau$, or for as long the threshold is breached. Longer standstills increase the discount of the $\mathrm{CoCo}$ (Figure 5). Choosing a very long standstill is akin to overpaying for insurance, as the sovereign offers debt at a discount for the option of a potential standstill that may be too long for its needs. There are many variations of the fixed standstill - such as extending principal maturity, single standstill for the first trigger event, multiple standstills etc - but we do not discuss all the alternatives. (The model of Consiglio, Tumminello, and Zenios (2016b) can price these variations.)

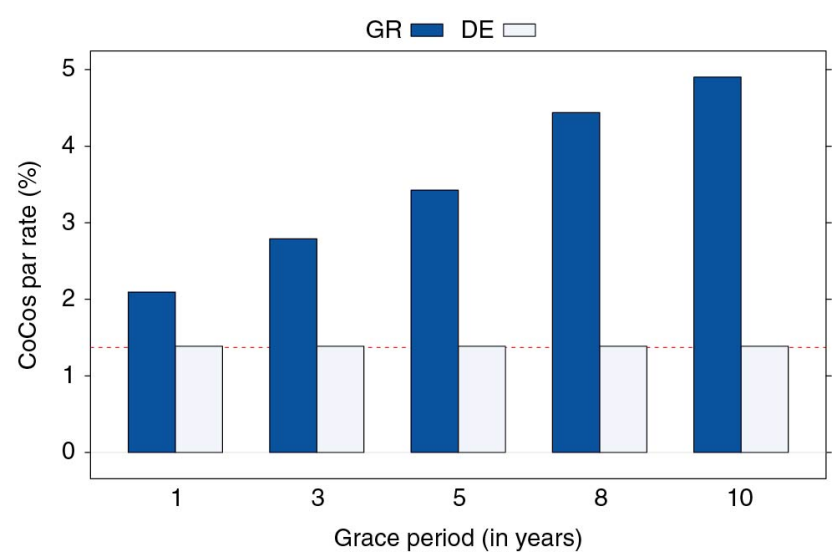

Figure 5: Par yields for S-CoCo increase for longer grace periods, as illustrative here for threshold 500bp. Source: Consiglio, Tumminello, and Zenios (2016b).

An alternative approach is to have payment standstill for as long the trigger exceeds the threshold. This makes $\Delta \tau$ a random variable. This standstill is more effective in forestalling crises but it may be less attractive for buyers. The pricing model applies for random $\Delta \tau$ with marginal increase in computational complexity. For periods of low CDS spread volatility we expect the S-CoCo with stochastic standstill mechanisms to be priced closer to the short grace periods instruments, and as volatility increases the prices increase towards the longer grace periods. This was observed numerically when using the model.

\subsection{False Alarms and Missed Crises}

Can S-CoCo fail? Of course they can, and McDonald (2013) suggests that the language of statistical hypothesis testing provides the terminology for discussing failures. The case when a standstill is triggered when the sovereign does not need it is a type I error, i.e. a false positive. If S-CoCo fails to trigger when the sovereign needs it we have type II error, i.e. a false negative.

Type I error. This is a false positive, and the standstill is triggered when the sovereign does not need it. The situation can be easily reversed by continuing timely payments. Transaction costs are minimal, as opposed to B-CoCo type I errors when the bank has to buy back the newly issued shares. 
Type II error. This is a false negative and the S-CoCo fails to trigger when the sovereign enters a liquidity crisis. The sovereign does not benefit from the standstill and suffers the consequences of a prolonged crisis. Even worse, the sovereign paid a price for issuing S-CoCo but does not benefit from risk sharing with its creditors. The S-CoCo could fail if the threshold is too high. Given that type I errors are less costly and easily corrected, the threshold would rather be on the low side. However, the country pays higher premium for lower threshold, Figure 4, so it can not be too low.

It is also possible to have a failure of the trigger mechanism. For instance, in Figure 2 we observe a big drop of Cyprus spreads in Oct.-Nov. 2011 as a result of a bi-lateral loan from Russia that eased the pressure on the sovereign without addressing the underlying imbalances. If Cyprus had negotiated this loan around May 2011 it would have kept its CDS spread below the threshold and avoid triggering the S-CoCo. This is fine if the country uses the bi-lateral loan to address imbalances, but in this case the government was "gambling for redemption" and the S-CoCo conversion would have been delayed. Hence, unlike B-CoCo, type II errors depend on government action or, more precisely, inaction. S-CoCo can not protect a sovereign from itself.

Table 2 illustrates the standstill triggered dates for different thresholds for eurozone countries. At 500bp, used for illustration, we avoid type II errors. In the eurozone crisis all countries (except Cyprus) applied for assistance at CDS spreads circa 600bp, so a threshold 500bp would have avoided delays. However, for Italy and Lithuania we have Type I error. (We do not consider Bulgaria as a case of false alarm since the country was already benefiting from various financing facilities from the IMF and the World Bank.) At a threshold of 550 both false positives and false negatives are avoided. In the context of bank contingent capital, McDonald (2013) argues that type II errors are more serious than type I errors, and the same is true with S-CoCo.

Table 2: Date of example S-CoCo trigger for eurozone crisis countries for different threshold levels, with bold denoting the dates entering an IMF program (ESM for Spain).)

\begin{tabular}{|c|c|c|c|c|c|}
\hline \multirow[t]{2}{*}{ Country } & \multicolumn{5}{|c|}{ Trigger threshold } \\
\hline & 400 & 500 & 550 & 600 & 700 \\
\hline Bulgaria & $2008 S 2$ & $2008 S 2$ & $2009 S 1$ & $2009 S 1$ & \\
\hline Ireland & 2010S2 & 2010S2 & 2010S2 & 2011S1 & 2011S1 \\
\hline Greece & $2010 S 1$ & $2010 S 1$ & $2010 S 1$ & $2010 S 1$ & 2010S1 \\
\hline Spain & 2011S2 & 2012S1 & 2012S1 & & \\
\hline Italy & 2011S2 & 2011S2 & & & \\
\hline Cyprus & 2011S2 & 2011S2 & 2011S2 & 2011S2 & 2011S2 \\
\hline Lithuania & 2009S1 & 2009S1 & & & \\
\hline Portugal & $2010 S 2$ & 2011S1 & 2011S1 & 2011S1 & 2011S1 \\
\hline Slovenia & 2011S2 & & & & \\
\hline
\end{tabular}

At a threshold of 550 both false positives and false negatives are avoided. (Bulgaria was already benefiting from various financing facilities from the IMF and the World Bank.

\section{Challenges and the Role of the Official Sector}

There are several challenges in launching S-CoCo. For instance, sovereign CDS markets tend to be small and illiquid, or not available for some counties. This will necessitate the use of different market triggers. There is also first mover disadvantage, and while we have focused above on the long-term volatility premium, there are other costs, such as innovation premium for issuing novel instruments, and liquidity premium in the early launching stages. These premia are transient, but there is a first mover disadvantage which highlights the need for coordination (Demertzis and Zenios 2018). Furthermore, the regulatory treatment of these instruments on bank balance sheets will determine how banks, a major sovereign creditor, will respond to these instruments. $\mathrm{S}-\mathrm{CoCo}$ should remain risk free since capital is guaranteed and is as risk free as standard sovereign bonds.

These instruments could be potentially de-stabilizing if they cause flight to safety as the threshold is approached. We have seen that the sovereign's incentives are not aligned with manipulation, but market participants could create a self-fulfilling crisis by fleeing from a potential standstill as the spreads increase. Investors may also prefer that the standstill is triggered if short-term interest rates shift downwards, but that's when the sovereign would prefer to retire current debt and refinance its needs at the lower rates. A well known case of sovereign market manipulation was registered in December 1994, when hedge funds tried to trigger a knockout of a barrier option on Venezuelan Brady bonds. Merill Lynch, that had sold the option, used its financial muscle to keep prices below the threshold and on a single day (Dec. 9) \$1.5bn worth of the almost \$7bn market 
were traded. To make market manipulation difficult we suggest a trigger averaged over a long period (30 days). There is also a role for the official sector, which we discuss below.

We could potentially use a broad market index to activate a trigger, thus accounting for systemic risk. McDonald (2013) advocates that bank CoCo be triggered when the threshold is breached during systemic crises, but the bank goes bankrupt during idiosyncratic crises. Although we do not find that his arguments apply to sovereigns, since sovereigns can not go bankrupt, we can consider situations whereby the standstill is triggered if the CDS threshold is breached during a systemic crisis but for idiosyncratic crises there would be no payment standstill and the sovereign will be cut off the market and require a debt renegotiation (akin to bankruptcy). For the systemic trigger we could use an indicator that measures overall investor sentiment with increased risk aversion and reduced liquidity, such as the CBOE volatility index VIX, or, for eurozone countries, the CDS spreads on the German bunds, or, for emerging markets, the EMBI index. The standstill would be triggered if the sovereign CDS threshold is breached during a systemic crisis measured by a market index, but not for idiosyncratic crises.

The existence of multiple equilibria has been of concern in the academic literature for B-CoCo (Sundaresan and Wang 2015). Interestingly, the international institutions (Avdjiev et al. 2017; IMF 2017) do not seem to consider this as a problem, and there is no empirical evidence. Several authors responded with remedies to the multiple equilibria postulated by Sundaresn-Wang (McDonald 2013; Calomiris and Herring 2013; Avdjeiv et al. 2015). Glasserman and Nouri (2016) tighten the conditions of the Sundaresan-Wang model, so multiple equilibria are more difficult to realise even in theory, Pennacchi and Tchistyi (2016) show that the multiple equilibrium problem disappears for perpetuities, and Chen et al. (2013) find that the values are continuous across the trigger, although there is a discontinuity in the derivative.

$\mathrm{S}-\mathrm{CoCo}$ are different from B-CoCo in a fundamental way that further reduces multiple equilibrium risks. In $\mathrm{B}-\mathrm{CoCo}$ multiple equilibria arise because the conversion creates equity, and dilution changes the equity prices that triggered the conversion. In the case of S-CoCo the price of one type of instrument (CDS spreads) is used to trigger the event, but the event is not a conversion to CDS but a change of payment schedule. There is an indirect effect that CDS spreads will be affected by the standstill. In the long run, the spreads will decline if the government effectively addresses imbalances during the grace period, but it is hard to tell a priori what will be the short term reaction. Spreads could be reduced, since the standstill helps the sovereign avoid defaults, thereby creating negative feedback with potential for multiple equilibria. Or, they could increase, since the adverse signal of a standstill raises concerns about ability to pay standard bonds, thereby creating a positive feedback reinforcing the trigger signal. Or, they can remain unchanged since payments missed during the grace period have to be paid back later. So, the problem of multiple equilibria remains a matter of speculation that can be resolved only empirically, much like the debate the preceded the introduction of collective action clauses (CACs). We will see how the official sector can play a role to mitigate multiple equilibria eventuality.

Another related issue is that the markets eventually will price the action taken based on the trigger, and the market based trigger will not be informative (Bond, Goldstein, and Prescott 2010). For as long there are simple (non-contingent) bonds for a sovereign and CDS on these bonds, there is no feedback from the action (i.e. payment standstill) and the value of the CDS spread trigger. If, however, S-CoCo are widely accepted and become the only (or predominant) instrument for sovereign financing then CDS spreads on S-CoCo could become less informative as a trigger: they will encompass both the fundamentals of the sovereign and the effect of the action to be taken. We discuss CDS endogeneity in Section 6.3.

There are several potential solutions to this eventuality. Sovereigns could be required to issue sufficient volume of simple debt to act as an indicator, the same way that regulators require banks to issue subordinated debt to provide an alternative indicator of a bank's health in addition to stock prices. Or, following Bond, Goldstein, and Prescott (2010), we could introduce triggers based on the prices of multiple traded securities, bringing more transparency of the sovereign's information in triggering a standstill, or introduce a security that pays off in the event that the sovereign takes a corrective action (a prediction market). Of course the models would need to be calibrated on the data of the prediction market. Prescott (2012) comments that a prediction security does not exist for B-CoCo triggers, but he points out that "credit default swaps are very close in that they are essentially insurance contracts that pay out in the event of a default. If a credit default swap was designed so that conversion was the triggering default event, then the swap could be used as the prediction security." In the case of sovereign debt, CDS exist and the introduction of CDS for S-CoCo will provide both a hedging instrument for S-CoCo investors and a prediction security.

\subsection{The Role of the Official Sector}

While the literature does not provide compelling evidence about potential problems with an automatic market trigger, the important decision of a standstill should not be left solely to the market. For instance, we have seen that Lithuania and Italy could recover without IMF assistance. (Although, in today's environment, the 
statement about Italy sounds ironic.) Hart and Zingales (2011) argue for the role of a regulator to mediate the automatic triggering of B-CoCo, and the European Stability Mechanism could play this role for S-CoCo of eurozone sovereigns under its jurisdiction. The possibility of maturity extensions for countries entering an ESM program has been suggested by the former German Minister of Finance Wolfgang Schäuble (Bastasin 2015) and the Council of Economic Experts (Andritzky et al. 2016). Buchheit et al. (2013) also suggested modifications to the ESM treaty to make debt restructuring a pre-condition for assistance. S-CoCo could be the instrument for implementing such policy changes, with ESM requesting all countries covered by its mandate to issue S-CoCo. This would promote and incentivize these instruments in the eurozone.

In this case the extension will not be fully automatic but will require discretion. In particular, if the threshold is breached the ESM will carry out a debt sustainability analysis (Athanasopoulou et al. 2018), as already prescribed in ESM Treaty Article 13 1.b. If the analysis determines that debt is sustainable, and the breach is not justified, the ESM would not activate the standstill and commit some resources to prove its confidence to the sovereign. This would reassure the markets. The commitment should be unconditional and pari passu with existing financial debt to avoid ESM forbearance. The interest rate on the committed financing should be lower than the prevailing financing rates for the sovereign, but not much lower so the sovereign has incentives to correct any imbalances and benefit from lower market refinancing rates.

If the analysis determines that the breach is justified, the standstill will be activated and the country will enter an adjustment program with ESM senior financing under strict conditionality. This staged approach is automatically triggered avoiding delays, which is one of the motivations for S-CoCo. It avoids bear raids since the ESM sustainability analysis and commitment for funding could reduce spreads and impose losses on the raiders. It is also consistent with policy suggestions for risk sharing between ESM and the markets (Demertzis and Zenios 2018). Since the official sector does not need to pay-out existing bond holders, it can support a more gradual economic adjustment path. Finally, we do not preclude additional measures (e.g. haircut) at the end of the grace period in the case of insolvency, as suggested by Andritzky et al. (2016). However, due to the automatic standstill more private creditor shoulders will be available to carry the burden.

\section{$5 \quad$ A Risk Management Model with Sovereign Contingent Debt}

We develop now a risk management model to incorporate S-CoCo in sovereign debt. The objective is to optimize debt financing decisions in the short-, medium-, and long-term. The model determines a portfolio of debt instruments by maturity, with or without contingent standstill provisions. Portfolio choices are evaluated for their expected cost and risk of the cost distribution. Cheaper debt financing is possible - usually with short term borrowing using plain bonds - but with higher risk. The model traces a frontier that trades off expected cost with tail risk for the sovereign. This is the risk profile for a given debt structure and a set of debt financing instruments. We use the model as a "proof of concept" of the gains from financing sovereigns with contingent debt, but further work is needed to develop a practical model (Section 7).

The model extends our earlier work (Consiglio and Zenios 2016) to include S-CoCo. In the previous paper we used the model to reschedule or restructure debt so that it becomes sustainable. The present paper models automatic rescheduling using S-CoCo, and demonstrates improvements in a country's risk profile. The improvements are anticipated from optimization theory, as the model with S-CoCo has larger feasible region than the model with plain debt instruments. The significance of the model is that it quantifies the improvements to study alternative S-CoCo designs. A fully developed and calibrated model provides a tool for analyzing proposals emerging from the debate on sovereign contingent debt.

The model is a discrete state-space, discrete time-space multi-period stochastic program, see, e.g. (Zenios 2007, chap. 5). Decisions are made here-and-now based on all available information and anticipating future uncertain information. As new information arrives we have recourse decisions that are conditioned on the received information and the outcome of previous decisions. Stochastic programming finds numerous applications in asset/liability management, see the handbook Zenios and Ziemba (2007) and extensive bibliography therein.

\subsection{The Scenario Setting}

We use a discrete set of time-stages when decisions are made $\mathscr{T}=\{0,1,2, \ldots T\}$. We denote by $t \in \mathscr{T}$ the time index, where $t=0$ indicates here-and-now and $T$ is the risk horizon. At each time instance $t$, economic and financial parameter dynamics follow some stochastic processes, possibly correlated, on a scenario tree, such as the one of Figure 6. Parameters take values from a finite set indexed by the set of nodes $\mathcal{N}_{t}$, where each node $n \in \mathcal{N}_{t}$ represents possible states of the economy at time $t$. Not all nodes at $t$ can be reached from every node at $t-1$ and we define paths from root node 0 to final nodes in $\mathcal{N}_{T}$ to denote the unique way of reaching each 
terminal node. Each path is a scenario. Our example tree has 12 scenarios, two possible states at $t=1$, three at $t$ $=2$, and six at $t$. We denote by $\mathscr{P}(n)$ the set of nodes on the unique path from the root node to $n \in \mathcal{N}_{t}$, and by $p(n)$ the unique predecessor node for $n$, with $p(0)$ being empty. For a given node $n$ all information on the path $\mathscr{P}(n)$ is known.

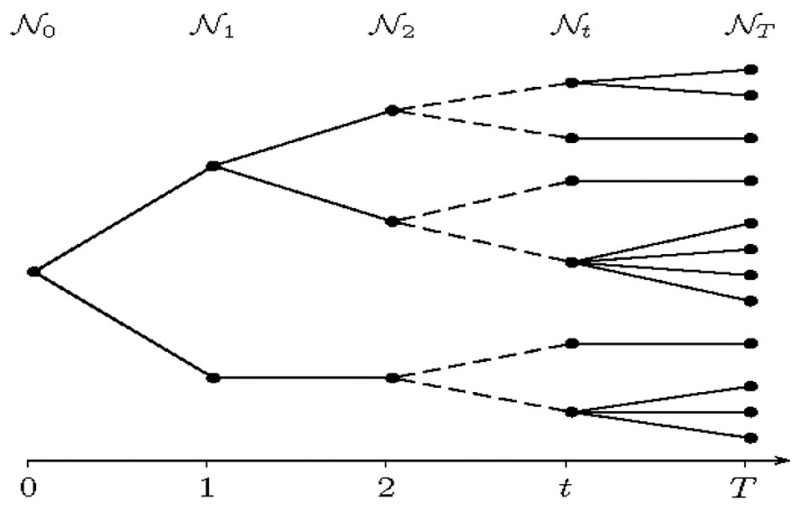

Figure 6: A scenario tree.

There have been significant advances in the calibration of scenario trees to match market observed moments for multiple risk factors for use in stochastic programming (Høyland and Wallace 2001; Klaassen 2002). Consiglio, Carollo, and Zenios (2016a) developed an arbitrage-free calibration procedure to match an arbitrary number of moments and obtain both risk neutral and objective probabilities, and is well suited for fitting trees to financial (risk free rates, CDS spreads), macroeconomic (GDP growth), and fiscal (primary balance) variables, as needed for our model.

\subsection{Tradeoffs: Expected Cost and Tail of Debt Probability Distribution}

Before we give the dynamics of debt on the scenario tree we calculate the cost of debt financing decisions at the risk horizon. Denote by $C^{n}$ the total amount due at each end node $n \in \mathcal{N}_{T}$. This variable adds up maturing debt, payments due to borrowing at nodes on the path leading to $n$, and the market price of any outstanding debt. Its dynamics are given later. Let $Y^{n}$ denote GDP, and consider the ratio $c^{n}=C^{n} / Y^{n}$ as a key indicator for debt sustainability (Sturzenegger and Zettelmeyer 2006, pp. 308-313). $c^{n}$ is a random variable whose distribution depends on debt financing decisions, on the term structure of debt, on the economic and financial random variables, and, when using S-CoCo, on payment standstills. We optimize the risk of this distribution.

Its expected value is given by

$$
\mathbb{E}[c]=\sum_{n \in \mathcal{N}_{T}} \pi^{n} c^{n},
$$

where $\pi^{n}$ are the probabilities of terminal states. This is the expected debt-to-GDP ratio accounting for the cost of debt financing. In the context of standard debt sustainability analysis this would be the future value of debt-to-GDP ratio under some projection of growth and debt financing rates. However, we employ a range of plausible scenarios with their associated probabilities and calculate the expectation and a measure of risk, instead of using only the expected value projections.

To assess the risk of deviations from the mean we need a risk measure. We define the stress debt for each terminal state as the non-negative difference of state-dependent debt-to-GDP ratio from the mean

$$
s d^{n}=\max \left[0, c^{n}-\mathbb{E}[c]\right] .
$$

Stress debt signals one-sided deviations of debt-to-GDP ratio from the mean. Following Artzner et al. (1999), we use a coherent risk measure on stress debt, which we call Conditional Debt-at-Risk (CDeaR). This is the expected value of stress debt, conditioned on stress debt exceeding its Value-at-Risk at a given confidence level $\alpha$, which we call Debt-at-Risk (DeaR). CDeaR is the well known conditional Value-at-Risk (CVaR) of the finance literature or the expected shortfall of the insurance literature, and provides a bound on the Value-at-Risk, which is used by bank and insurance regulators in Basel III and Solvency II, respectively. 


\subsection{Model Parameters, Variables, and Dynamics}

We formulate now the model. First we define the decision variables and parameters, and then give the debt dynamics. Without ambiguity we drop the time index since each node $n$ takes values from a time-indexed set $\mathcal{N}_{t} . j=1,2, \ldots, J$, denotes debt instruments of different maturities. The model determine the maturity of instrument to be used at each state $n \in \mathcal{N}$ to finance the debt, using variables:

a. Vector of debt financing decisions at node $n . x^{0}$ is the here-and-now decision and $x^{n}$ are future decisions conditioned on the state of the economy $n \in \mathcal{N}_{t}$ at $t$. We drop the time index and the decision vector at each node is given by $x^{n}=\left(x^{n 1}, x^{n 2}, \ldots x^{n j}, \ldots x^{n J}\right) \cdot x^{n j}$ denote nominal amount issued at the $n$th node with maturity $j$, using simple bonds or S-CoCo. [To develop a model that includes both types of instruments we need vectors $x_{\mathrm{No}-\mathrm{CoCo}}^{n}$ and $x_{\mathrm{CoCo}}^{n}$, but we do not formulate this. Deciding how much to hedge sovereign risk using S-CoCo and how much to leave un-hedged with straight bonds is an important question, see for instance Froot, Scharfstein, and Stein (1993).]

The model parameters are the following:

$D^{n}$ Legacy debt stock to be financed.

$\mathrm{CF}^{\mathrm{j}}(n, m)$ Cash flows at node $n$ for bond with maturity $j$ issued at some node $m$ on the path $P(n)$ leading to $n$. The timing of cashflows from S-CoCo is contingent on the trigger.

$P^{j}(n, m)$ State-dependent value of outstanding debt at node $n$ for debt with maturity $j$ issued at node $m$ on path $P(n) . P^{j}(n, n)$ is the price at the state when a bond is issued.

$O^{n}$ Payments due at each node $n$ based on borrowing at nodes on path $P(n)$.

To model standstills we introduce a triggering parameter $\delta$, with value $\delta^{n}$ on node $n$, and associated binary variable $z^{n}$ to activate the standstill. In particular, payments to S-CoCo holders proceed according to schedule if the threshold is not exceeded, otherwise payments are delayed for the grace period. The following integer programming construct models standstill for each node $n$ when the indicator exceeds the threshold:

$\delta^{n}$ is the difference of the indicator value from the threshold.

For CDS indicator we have $\delta^{n}=s^{n}-\bar{s}$ where $s^{n}$ is the sovereign spread of CDS and $\bar{s}$ is the threshold. If indebtedness is the indicator we set $\delta^{n}=d^{n}-\bar{d}$ where $d^{n}$ is debt-to-GDP ratio and $\bar{d}$ is a threshold.

$z^{n}$ is a binary variable.

It is easy to verify that, for a large positive constant $\mathcal{M}$, the following system of inequalities sets $z^{n}=0$ if the indicator exceeds the threshold, and $z^{n}=1$ otherwise:

$$
\begin{gathered}
\delta^{n} \geq-\mathscr{M} z^{n} \\
\delta^{n} \leq \mathscr{M}\left(1-z^{n}\right) .
\end{gathered}
$$

Now we express debt dynamics in terms of model parameters and variables. At each node $n \in \mathcal{N}$ the amount of new debt is given by the total payments to all instruments - principal and/or coupon - that were issued at some node on path $P(n)$, times the total amount issued:

$$
O^{n}=\sum_{m \in \mathscr{P}(n)} \sum_{j=1}^{J} x^{m j} \mathrm{CF}^{j}(n, m) .
$$

The total debt to be raised at node $n$ has to finance legacy debt plus any debt obligations created from previous financing decisions. The binary variable is used to trigger the standstill, and we have

$$
\sum_{j=i}^{J} x^{n j} P^{j}(n, n)=D^{n} z^{n}-\sum_{m \in p(n)} D^{m}\left(1-z^{m}\right)+O^{n} .
$$

At each terminal node $n \in \mathcal{N}_{T}$, we have the cost of financing decisions 


$$
C^{n}=D^{n}+\sum_{m \in p(n)} D^{m}\left(1-z^{m}\right)+O^{n}+\sum_{m \in \mathscr{P}(n)} \sum_{j=1}^{J} x^{m j} P^{j}(n, m),
$$

or, scaled by GDP, as $c^{n}=C^{n} / Y^{n}$. The four terms in the right-hand-side of (7) are the debt that matures at the risk horizon, plus debt whose maturity was extended from a previous node on the path due to standstill, plus obligations created from previous financing decisions, plus the market value of debt instruments that mature past the risk horizon. The cost is endogenous to the model, with expected value given by eq. (1). Following Consiglio and Zenios (2016) we use the risk measure CDeaR of $c^{n}$, which is represented using Rockafellar and Uryasev (2000) by the system of equation and inequalities

$$
\begin{gathered}
\text { CDeaR }=\zeta+\frac{1}{1-\alpha} \sum_{n \in \mathcal{N}_{T}} \pi^{n} y_{+}^{n}, \\
y_{+}^{n} \geq s d^{n}-\zeta, \\
y_{+}^{n} \geq 0,
\end{gathered}
$$

where $y_{+}^{n}$ is a dummy variable denoting the non-negative values of debt in excess of $\zeta$. $\zeta$ is the Value-at-Risk of debt (DeaR), i.e. the lowest possible value so that the probability of excess debt not exceeding DeaR is $(1-\alpha)$. The full model minimizes the expected cost of debt financing with parametric limits on risk to obtain the risk profile, see Appendix B.

\section{The Case Study of Greece}

Greece is a good candidate for S-CoCo financing and in this section we use Greek debt data to perform two experiments. We have already seen that if Greece debt was in S-CoCo the country would have received a warning 4 months before it signed an agreement with IMF, and would have benefited from a payment standstill about 20 months before the eventual debt restructuring with the PSI. In this section we show, first, how the situation could have been better if debt was in S-CoCo, and, second, how to move Greece forward using contingent debt. For a discussion of the Greek crisis see Zettelmeyer, Trebesch, and Gulati (2013).

Greece was also used as a case study in Consiglio and Zenios (2016) to identify appropriate debt rescheduling and / or nominal value haircuts to render Greek debt sustainable. We use the exact same problem setting in the present experiments. The country's debt with a 4-stage discretization and two alternative reschedulings are shown in Figure 7. From the several model instances solved in Consiglio and Zenios (2016) we use the setup for their Figure 14, where debt was financed in its current form and under the two hypothetical reschedulings. Our experiments illustrate that S-CoCo would have, qualitatively and quantitatively, similar impact like the reschedulings that come after long negotiations. 

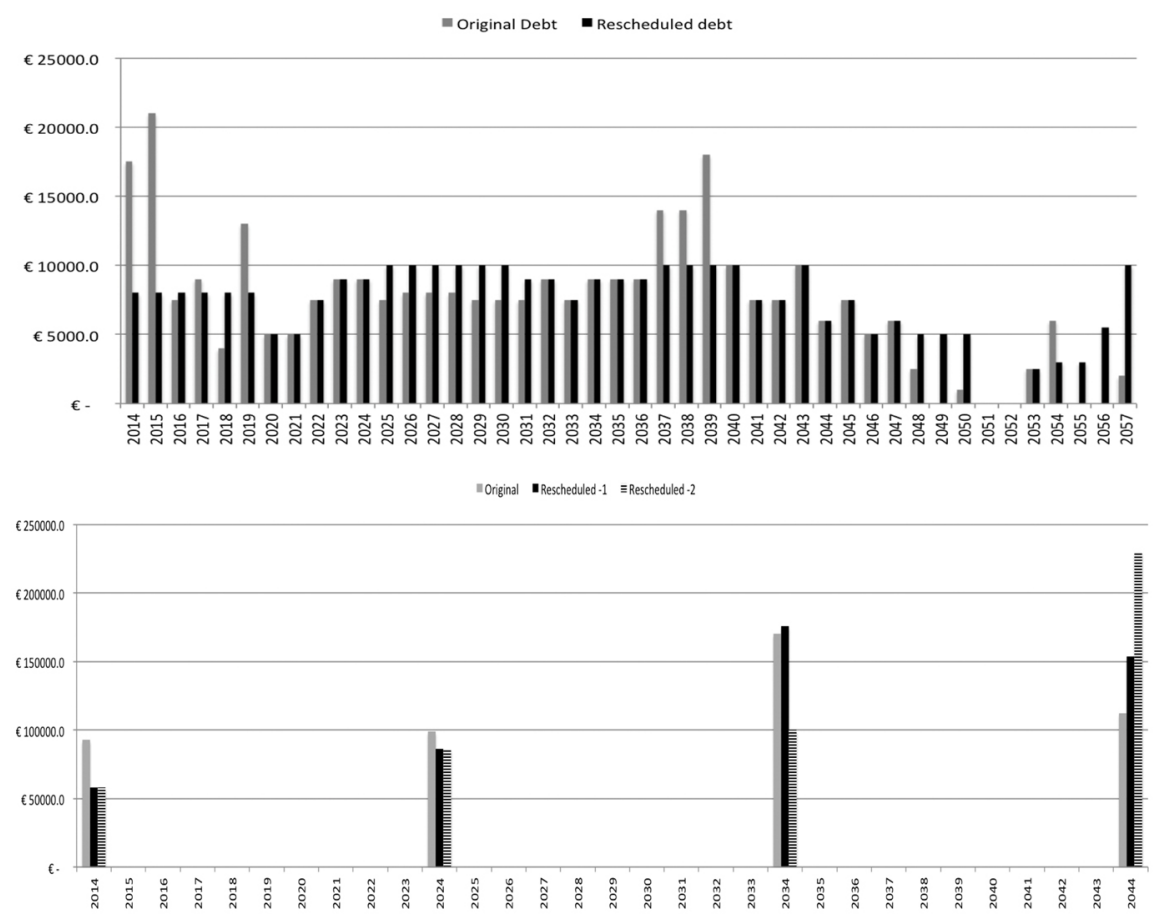

Figure 7: Greece debt profile and 4-stage discretization with two hypothetical reschedulings. Source: Consiglio and Zenios (2016)

Details of the scenario tree calibration are given in the reference and we emphasize that runs with and without S-CoCo were done under strictly identical conditions so that conclusions can be drawn about the use of contingent debt. In particular, the stochastic process of the term structure of interest rates is generated using the simulator of Bernaschi et al. (2007) developed for public debt management of the Italian treasury. For GDP and primary surplus we use IMF projections as in Consiglio and Zenios (2016). To keep the current paper consistent with the scenario tree calibrated in our previous work we use debt-to-GDP ratio instead of the CDS trigger, as also advocated in Barkbu, Eichengreen, and Mody (2012), and choose the debt-to-GDP threshold to be consistent with the pricing model. For debt-to-GDP ratio 100\%, roughly the same proportion of scenarios trigger a standstill as with a CDS spread of 400bp, and we run the model using S-CoCo with discount prices 10\% corresponding to this threshold, and 5\% which is more favorable for the sovereign, in anticipation of reduced market spreads with the introduction of S-CoCo. Using debt-to-GDP proxy is a shortcut that allows us to build on the previous paper for a proof of concept. Choosing the debt-to-GDP threshold to correspond to a specific CDS threshold allows us to model the effects on a debt profile with appropriately priced S-CoCo, and this is the only point we make with this experiment.

We use the model to trace the risk profiles of the country with and without S-CoCo financing. When the risk profiles shift downwards - as is done when using S-CoCo - the expected debt-to-GDP ratio is lowered, with a commensurate decrease in probability of default. When the risk profiles shift to the right - as is done with S-CoCo - the tail risk of the debt-to-GDP ratio increases, because the grace period prolongs payments and introduces more uncertainty. However, the increase in tail risk is an order of magnitude smaller than the reduction of expected debt-to-GDP.

\subsection{Pre Bail-out: What Could Have Been}

In the first experiment, we run the model assuming that Greece could turn the clock back and accumulate all its debt in S-CoCo while it was enjoying low CDS spreads. Figure 8(A) shows the frontier of the expected cost of financing Greece debt against the tail risk, together with the frontier when using S-CoCo with zero discount, which is the best case for the sovereign. Two intermediate frontiers show the improvements with $5 \%$, which is favorable for the sovereign, and with the appropriate price discount $10 \%$. 

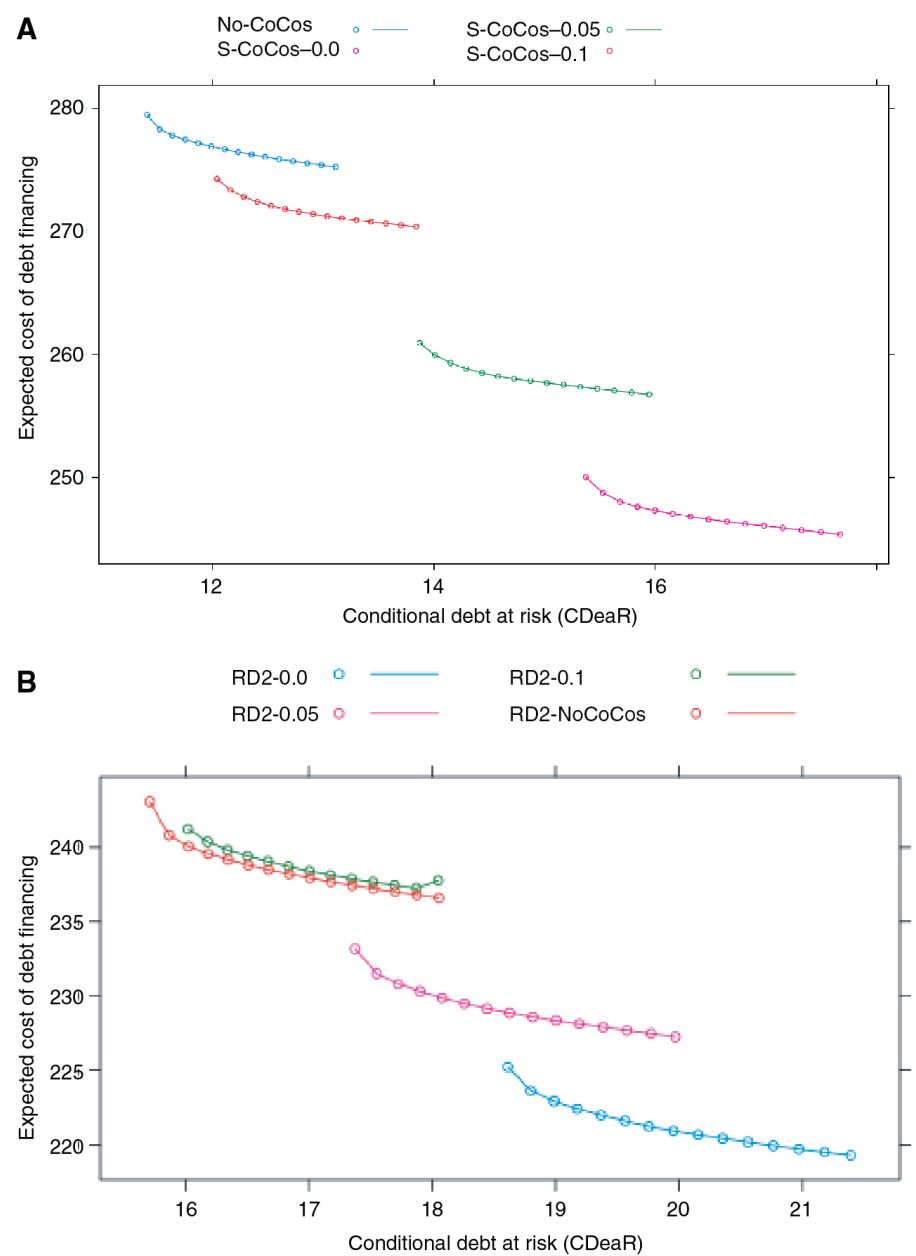

Figure 8: Risk profiles of Greece debt with S-CoCo issued pre bail-out (panel a) or post debt-relief (panel b), at discounts $0,5 \%, 10 \%$.

(a) S-CoCo issued before Greece faced a crisis; (b) S-CoCo issued after Greece regains market access.

We observe improvements in all cases. Comparing the left-most points of the frontiers we note, for instance, that with $5 \%$ price discount the expected cost of debt financing decreases by EUR 20bn, from $280 \mathrm{bn}$ to $260 \mathrm{bn}$, with an increase in tail risk by 3bn. The risk profile with the zero-cost S-CoCo is roughly the same with the profile obtained with the extension of debt maturities analysed in (Consiglio and Zenios 2016, Figure 14). The country's risk profile improves by the same order of magnitude from a standstill as could have been achieved with a rescheduling, but now the standstill is embedded in the contract, avoiding long delays and negotiation frictions.

The country's total financing needs reduce to about $140 \%$ of GDP. This does not restore sustainability, and exemplifies the fact that while S-CoCo benefit a country in a liquidity crisis, they do not resolve an insolvency crisis. Greece is a good example to highlight both the benefits and the limitations of S-CoCo. Eventually Greece received debt relief in the PSI and there would have been additional benefits from the S-CoCos. In particular, the standstill implies that less of the debt would have been replaced by senior official debt during the first Greek program, so when the inevitable restructuring took place, a wider pool would have been targeted and greater debt relief could have been realized.

\subsection{Post Debt-relief: A Way Forward}

The second experiment considers what happens if Greece receives debt relief - using the debt profile marked Rescheduled-2 in Figure 7, which was shown in our earlier paper to restore sustainability - and Greece reaccesses the market with rates similar to Italy. How would Greece benefit from replacing its debt with S-CoCo as part of the restructuring process? From the risk profiles in Figure 8(B) we observe again significant improvements with properly designed S-CoCo. If the S-CoCo is designed to be priced at 5\% discount, the risk profile improves with expected cost of debt financing decreasing by $10 \mathrm{bn}$, from $243 \mathrm{bn}$ to 233bn, and an increase of $1.5 \mathrm{bn}$ in tail risk. However, S-CoCo priced at $10 \%$ discount is expensive for the country and the risk profile is virtually identical to the profile without CoCo. 


\subsection{Discussion on CDS Spread Endogeneity}

Are the improvements Pareto efficient, in the sense that neither the creditor nor debtor are worse off? The risk profiles in Figure 8 refer to the debtor and we observe significant decrease in expected cost with marginal increases in risk. Hence, a risk neutral debtor is better off when using S-CoCo. The creditor, receives a discount in exchange for the potential standstill, and if pricing is fair he or she is neutral. These are Pareto improvements.

However, there is an important assumption underlying the pricing (and therefore the risk management) model. That is, S-CoCo issued as a small percentage of the country's debt do not materially change market data, namely the yield curve and associated CDS spreads. Our model is a partial-equilibrium model, using calibrated yield curve spreads based on observed market data from a market in equilibrium without S-CoCo. In the long-run S-CoCo could reduce yields and (i) plain bonds would be commanding a premium, and (ii) SCoCo discount will be smaller as a results of lower CDS spreads. With these price adjustments the risk profiles using S-CoCo or plain bonds should converge, and both debtor and creditor will be indifferent between S-CoCo and plain bonds. But any reduction in yields is due to lower default probabilities, with gains for both debtor and creditors as discussed in the introduction.

Further work is needed to develop a model with endogenous spreads, but even if such a model were available, there are no market data to calibrate it. So, we iterate by pricing S-CoCo and plain bonds using discount rates interpolated between the two extremes: (i) all debt is priced on the risk-free (e.g. German) yield curve assuming that default is eliminated with the issue of $\mathrm{S}-\mathrm{CoCo}$, and (ii) all debt is priced on the original Greek yield curve assuming no material change on default probabilities by issuing S-CoCo. Figure 9 shows the S-CoCo price converging to par when the Greek yield curve shifts downwards by approximately 80bp.

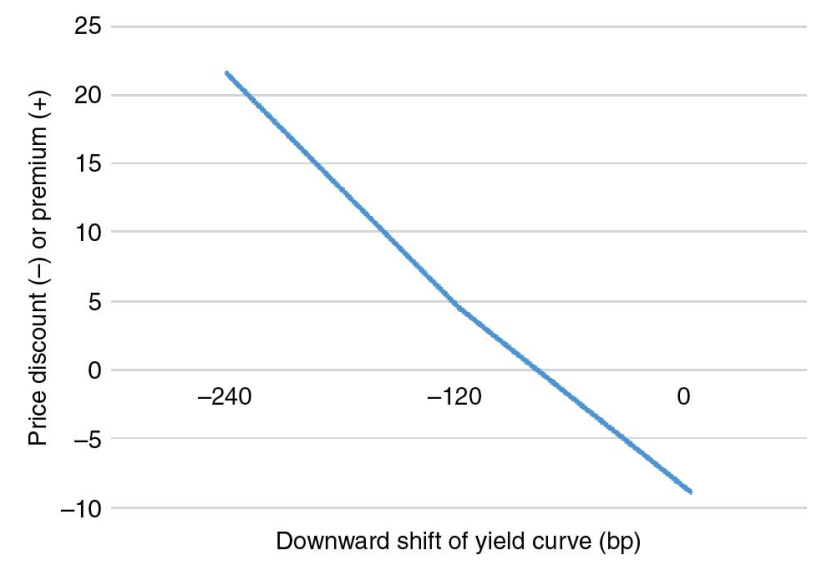

Figure 9: Variation of S-CoCo price with declining yield spreads shows convergence to par if the yield curve is reduced by about 80 bp by issuing S-CoCo.

\section{Conclusions}

Contingent bonds for sovereigns with a contractually specified standstill option are a stabilizing financial innovation that can forestall sovereign debt crises, or respond to one in a contractually pre-specified manner avoiding long delays that exacerbate the crisis. Literature on contingent contracts and neglected risks justifies this innovation. The paper has specified a general design of S-CoCo and discussed the choice of triggers, pricing and the incentives it creates, duration of the grace period, and errors of false alarms or missed crises. The official sector, such as the European Stability Mechanism in the eurozone, has a role to play in mediating the automatic standstill. We have seen how S-CoCo would have provided early warnings for eurozone countries, and significant savings for crisis countries, up to $4.10 \%$ of GDP in reduced debt servicing payments. A simple simulation for Greece highlights that GDP growth accelerates during a crisis if the country's debt was in $\mathrm{S}-\mathrm{CoCo}$, but the improvements erode with the premium demanded by the markets for buying S-CoCo.

A risk management model incorporating S-CoCo in debt financing was developed and calibrated on Greece crisis data. We have illustrated that the country could benefit both if it had issued either ex ante, or ex post, SCoCo. Obviously, S-CoCo can not be issued during the crisis, the same way one can not buy insurance when their house is on fire.

Extensions of this work would need to model the effect of significant issuance of sovereign contingent debt on the sovereign's yield curve, and develop models with multiple triggers to account for both systemic and idiosyncratic risks. A more convincing case could also be made by incorporating contingent debt in a more 
complete model of sovereign debt financing that accounts for both debt stock and flow, and interest rate endogeneity, such as the one developed for the European Stability Mechanism by Athanasopoulou et al. (2018).

While sovereign contingent debt creates the right incentives for fiscal discipline, to become a practical reality requires attention from policy makers, professional associations, and legal experts. In particular, there is need to clarify how these instruments will be treated by regulators when placed on the banks' balance sheet. To become a significant source of capital for sovereigns a solid investor base is needed. Understanding their merits and developing pricing models can encourage the participation of institutional investors, asset managers, insurers and pension funds, and develop the necessary market depth, volume, and liquidity.

\section{Acknowledgement}

The paper benefited from discussions with Maria Demertzis, Angel Gavilan, Anna Gelpern, Martin Guzman, Ashoka Mody, Edward Prescott and participants at the CIGI Conference on Sovereign Debt Restructuring at Columbia University, World Finance Conference at Buenos Aires, 5th International Conference of the Financial Engineering and Banking Society, 22nd Annual Conference of the Multinational Finance Society, and seminars at Bruegel, the Finance Department of the Wharton School, ORFE at Princeton University, the Norwegian School of Economics, and Stevens Institute of Technology. We thank Brice Dupoyet, Mark Walker, and an anonymous referee for extensive comments that led to refinement of some arguments and improvements of the presentation. We also thank David Pichler for excellent research assistance in the preparation of Tables 1-2 and Figure 3.

\section{Funding}

Stavros Zenios is holder of a Marie Sklodowska-Curie fellowship funded from the European Union Horizon 2020 research and innovation programme under grant agreement No. 655092.

\section{Appendix}

\section{A Calibration of CDS Spread and Spread Return Process}

We determine the parameters of the model for CDS spread return to identify its asymptotic dynamics. We start from the discrete time model of ( $\mathrm{O}^{\prime}$ Donoghue et al. 2014, cf. eq. (2), or eq. (6) without the jump term) and derive a set of conditions on the asymptotic moments to be matched with empirically estimated values. To simplify the notation in their eqs. (2) or (6), set $k_{0}=\gamma, k_{1}=\alpha+\beta$ and $k_{2}=\alpha \beta$, to get

$$
\Delta r_{t}=\left(k_{0}-k_{1} r_{t}-k_{2} \sum_{s=0}^{t} r_{s} \Delta t\right) \Delta t+\sigma w_{t} .
$$

$r_{t}$ is the return at $t$, and $w_{t} \sim \mathcal{N}(0, \Delta t)$. The simulation model is made up of two stochastic equations, one for the CDS and one for the interest rate, with identical structure given by (11). In case the two factors are correlated, we need two noise components, $\epsilon_{t}^{1}, \epsilon_{t}^{2} \sim \mathcal{N}(0, \Delta t)$, with $\rho\left(\epsilon_{t}^{1}, \epsilon_{t}^{2}\right)=0$. It can be easily shown that the two processes $w_{t}^{1}$ and $w_{t}^{2}$, given by

$$
\begin{gathered}
w_{t}^{1}=\epsilon_{t}^{1} \\
w_{t}^{2}=\rho \epsilon_{t}^{1}+\epsilon_{t}^{2} \sqrt{\left(1-\rho^{2}\right)},
\end{gathered}
$$

have correlation $\rho$, to be estimated from available historical time series.

Following O'Donoghue et al. (2014), for $t \rightarrow \infty$, we have

$$
\begin{gathered}
\mathbb{E}\left[r_{t}\right]=0 \\
\operatorname{var}\left[r_{t}\right]=\frac{\sigma^{2}}{2 k_{1}}
\end{gathered}
$$




$$
\begin{gathered}
\mathbb{E}\left[C_{t}\right]=\frac{k_{0}}{k_{2}} \\
\operatorname{var}\left[C_{t}\right]=\frac{\sigma^{2}}{2 k_{1} k_{2}},
\end{gathered}
$$

where $C_{t}=\sum_{s=0}^{t} r_{s} \Delta t$ and it is normally distributed.

The spread process $S_{t}=S_{0} \exp \left(C_{t}\right)$ is log-normally distributed with

$$
\begin{gathered}
\mathbb{E}\left[S_{t}\right]=S_{0} \exp \left(\frac{k_{0}}{k_{2}}+\frac{\sigma^{2}}{4 k_{1} k_{2}}\right) \\
\operatorname{var}\left[S_{t}\right]=S_{0}^{2} \exp \left(2 \frac{k_{0}}{k_{2}}+\frac{\sigma^{2}}{2 k_{1} k_{2}}\right)\left[\exp \left(\frac{\sigma^{2}}{2 k_{1} k_{2}}\right)-1\right] .
\end{gathered}
$$

We now have three equations in the four unknowns of the stochastic dynamics (11). We need one additional condition which we derive from the squared changes $\mathbb{E}\left[\left(\Delta r_{t}\right)^{2}\right]$, which is a measure of the smoothness of the process. With some standard assumptions for stochastic processes, namely that $\mathbb{E}\left[w_{t} C_{t}\right]=0, \mathbb{E}\left[r_{t} C_{t}\right]=0$ and $\mathbb{E}\left[r_{t} w_{t}\right]=0$, and using simple algebra, we obtain

$$
\mathbb{E}\left[\left(\Delta r_{t}\right)^{2}\right]=\frac{\sigma^{2}}{2}\left(k_{1}+\frac{k_{2}}{k_{1}}+2\right) .
$$

A sample estimate $\hat{s}^{2}$ for $\mathbb{E}\left[\left(\Delta r_{t}\right)^{2}\right]$ is given by

$$
\hat{s}^{2}=\frac{1}{N} \sum_{t=1}^{N}\left(r_{t}-r_{t-1}\right)^{2} .
$$

The theoretical moments defined by (15), (18), (19), and of the smoothness (20) are matched to the empirical observations. We denote by $\hat{S}$ the asymptotic CDS spread level, by $\hat{\sigma}_{S}$ the asymptotic variance of CDS spread level, by $\hat{\sigma}_{r}$ the asymptotic variance of CDS spread returns, and by $\hat{s}^{2}$ the smoothness of the CDS spread level. These quantities are estimated for each regime detected in the empirical data (Consiglio, Tumminello, and Zenios 2016b, Table 2). Denoting by $T_{\tau}$ the set of time periods in regime $\tau$, we obtain the moment estimates for the regime

$$
\begin{gathered}
\hat{S}=\frac{1}{\left|T_{\tau}\right|} \sum_{t \in T_{\tau}} S_{t} \\
\hat{\sigma}_{S}^{2}=\frac{1}{\left|T_{\tau}\right|} \sum_{t \in T_{\tau}}\left(S_{t}-\hat{S}\right)^{2} \\
\hat{\sigma}_{r}^{2}=\frac{1}{\left|T_{\tau}\right|} \sum_{t \in T_{\tau}}\left(r_{t}-\hat{r}\right)^{2} .
\end{gathered}
$$

Similarly, we have the estimate of the smoothness of the regime

$$
\hat{s}^{2}=\frac{1}{\left|T_{\tau}\right|} \sum_{t \in T_{\tau}}\left(r_{t}-r_{t-1}\right)^{2} .
$$

If $S_{0}$ denotes the starting value of the CDS spread for the selected regime, we can match the theoretical moments to their estimated values solving the system of nonlinear equations in $k_{0}, k_{1}, k_{2}$ and $\sigma$,

$$
\exp \left(\frac{k_{0}}{k_{2}}+\frac{\sigma^{2}}{4 k_{1} k_{2}}\right)=\frac{\hat{S}}{S_{0}}
$$




$$
\begin{gathered}
\exp \left(2 \frac{k_{0}}{k_{2}}+\frac{\sigma^{2}}{2 k_{1} k_{2}}\right)\left[\exp \left(\frac{\sigma^{2}}{2 k_{1} k_{2}}\right)-1\right]=\frac{\hat{\sigma}_{S}^{2}}{S_{0}^{2}} \\
\frac{\sigma^{2}}{2 k_{1}}=\hat{\sigma}_{r}^{2} \\
\frac{\sigma^{2}}{2}\left(k_{1}+\frac{k_{2}}{k_{1}}+2\right)=\hat{s}^{2} .
\end{gathered}
$$

The closed form solution to the system of equations (26)-(29) is given by

$$
\begin{gathered}
k_{0}=\frac{\hat{\sigma}_{r}^{2}}{\log \left(1+\frac{\hat{\sigma}_{S}^{2}}{\hat{S}^{2}}\right)} \log \left(\frac{\hat{S}}{S_{0}}\right)-\frac{1}{2} \hat{\sigma}_{r}^{2} \\
k_{1}=\frac{\sigma^{2}}{2 \hat{\sigma}_{r}^{2}} \\
k_{2}=\frac{\hat{\sigma}_{r}^{2}}{\log \left(1+\frac{\hat{\sigma}_{S}^{2}}{\hat{S}^{2}}\right)} \\
\sigma^{2}=2 \hat{\sigma}_{r}^{2}\left[-1+\sqrt{1+\frac{\hat{S}^{2}-k_{2} \hat{\sigma}_{r}^{2}}{4 \hat{\sigma}_{r}^{2}}}\right] .
\end{gathered}
$$

Finally, to ensure that $\sigma \in \mathbb{R}^{+}$we need $\hat{s}^{2}-k_{2} \hat{\sigma}_{r}^{2}>0$. [A full pricing model for sovereign CoCo is given in Consiglio, Tumminello, and Zenios (2016b).]

\section{B The Complete Model}

The model minimizes the expected cost of debt financing decisions with a parametric limit $\omega$ on risk. By varying $\omega$ we obtain the risk profile. This model extends Consiglio and Zenios (2016) with the introduction of binary variables to model payment standstill. The extended model is computationally more complex, but for as long we stay with a linear risk measure, we have a mixed integer linear program that can be solved using off-the-shelf optimization software. For our numerical work we use CPLEX from GAMS Development Corporation (2016).

$$
\begin{gathered}
\begin{array}{c}
\text { Minimize } \mathbb{E}[c] \\
\text { s.t. }
\end{array} \\
O^{n}=\sum_{m \in \mathscr{P}(n)} \sum_{j=1}^{J} x^{m j} \mathrm{CF}^{j}(n, m) \text {, for all } n \in \mathcal{N}_{t}, t \in \mathscr{T} \backslash 0 \\
\sum_{j=i}^{J} x^{n j} P^{j}(n, n)=D^{n} z^{n}-\sum_{m \in p(n)} D^{m}\left(1-z^{m}\right)+O^{n}, \text { for all } n \in \mathscr{N} \\
C^{n}=D^{n}+\sum_{m \in p(n)} D^{m}\left(1-z^{m}\right)+O^{n}+\sum_{m \in \mathscr{P}(n)} \sum_{j=1}^{J} x^{m j} P^{j}(n, m), \text { for all } n \in \mathcal{N}_{T} \\
\delta^{n} \geq-\mathscr{M} z^{n}, \text { for all } n \in \mathscr{N}
\end{gathered}
$$




$$
\begin{gathered}
\delta^{n} \leq \mathscr{M}\left(1-z^{n}\right), \text { for all } n \in \mathcal{N} \\
c^{n}=C^{n} / Y^{n}, \text { for all } n \in \mathcal{N}_{T} \\
s d^{n}=c^{n}-\mathbb{E}[c], \text { for all } n \in \mathcal{N}_{T} \\
y_{+}^{n} \geq s d^{n}-\zeta, \text { for all } n \in \mathcal{N}_{T} \\
\zeta+\frac{1}{1-\alpha} \sum_{n \in \mathcal{N}_{T}} \pi^{n} y_{+}^{n} \leq \omega \\
x^{n}, O^{n}, c^{n}, y_{+}^{n} \geq 0, \text { for all } n \in \mathcal{N} .
\end{gathered}
$$

\section{Notes}

1 Paragraph 11 of Communiquè G20 Finance Ministers and Central Bank Governors Meeting, G20 Web Site, 28 July 2016, available at http://www.g20.utoronto.ca/2016/160724-finance.html, last accessed February 14, 2018.

2 Calculated from the relation $p=\operatorname{spread} /(1-R)$ for recovery rate $R$ assumed to be $50 \%$.

3 Estonia and Latvia did receive IMF assistance, but Estonia did not have CDS so we could not monitor a potential S-CoCo, and Latvia had a very illiquid CDS trading at constant spread 82.46 since January 2008.

4 The incentives from B-CoCo on bank management are discussed by Himmelberg and Tsyplakov (2014) where they explain a very intuitive behavior: if conversion terms are dilutive for existing shareholders, banks have incentive to reduce the likelihood of triggering, leading to less defaults and lower borrowing costs, and Calomiris and Herring (2013) argue that B-CoCo is a poison pill for the bank management that triggers it, as both diluted shareholders and converted B-CoCo owners hold management responsible.

\section{References}

Acharya, V., and S. Steffen. 2015. “The ‘Greatest' Carry Trade Ever? Understanding Eurozone Bank Risks." Journal of Financial Economics 115: 215-236.

Andritzky, J., D. I. Christofzik, L. Feld, and U. Scheuering. 2016. "A Mechanism to Regulate Sovereign Debt Restructuring in the Euro Area." Working Paper 6038, CESIfo, February 2016.

Artzner, P., F. Delbaen, J. Eber, and D. Heath. 1999. “Coherent Measures of Risk.” Mathematical Finance 9 (3): 203-228.

Athanasopoulou, M., A. Consiglio, A. Erce, A. Gavilan, E. Moshammer, and S. A. Zenios. 2018. Risk Management for Sovereign Financing within a Debt Sustainability Framework. Risk Management for Sovereign Financing within a Debt Sustainability Framework. Working Paper Series. Vol. 31. Luxembourg: European Stability Mechanism.

Avdjeiv, S., A. Kartasheva, and B. Bogdanova. 2013. “Cocos: A Primer.” BIS Quarterly Review 43-56.

Avdjeiv, S., P. Bolton, W. Jiang, A. Kartasheva, and B. Bogdanova. 2015. “Coco Bond Issuance and Bank Funding Costs.” Working paper, Bank for International Settlement.

Avdjiev, S., B. Bogdanova, P Bolton, W. Jiang, and A. Kartasheva. 2017. “CoCo Issuance and Bank Fragility.” Working Papers 678, Bank for International Settlements.

Barkbu, B., B. Eichengreen, and A. Mody. 2012. "Financial Crises and the Multilateral Response: What the Historical Record Shows." Journal of International Economics 88 (2): 422-435.

Bastasin, C. 2015. “Mr. Schäuble's Ultimate Weapon: The Restructuring of European Public Debts." Opinion, Brookings Institution.

Bazerman, M. H., and J. J. Gillespie. 1999. "Betting on the Future: The Virtues of Contingent Contracts." Harvard Business Review.

Beers, D. T., and J-S. Nadeau. 2015. “Database of Sovereign Defaults, 2015.” Technical Report No. 101, Bank of Canada.

Benjamin, D., and M. L. J. Wright. 2009. "Recovery Before Redemption: A Theory of Delays in Sovereign Debt Renegotiations." Technical report, Available at SSRN: http://ssrn.com/abstract=1392539.

Bernaschi, M., M. Briani, M. Papi, and D. Vergni. 2007. “Scenario-generation Methods for an Optimal Public Debt Strategy.” Quantitative Finance 7: 217-229.

Blanco, R., S. Brennan, and I. Marsh. 2005. “An Empirical Analysis of the Dynamic Relation between Investment-grade Bonds and Credit Default Swaps." The Journal of Finance 60 (5): 2255-2281.

Bögli, A., and F. Fattinger. 2015. "European Puttable Bonds: An Alternative Instrument for Managing the Sovereign Debt Crisis." Available at ssrn: http://ssrn.com/abstract=2668176, Swiss Finance Institute.

Bond, P., I. Goldstein, and E. S. Prescott. 2010. "Market-based Corrective Actions." Review of Financial Studies 23 (2): 781-820.

Borensztein, E., P. Mauro, M. Ottaviani, and S. Claessens. 2004. “The Case for CDP-indexed Bonds.” Economic Policy 19 (38): 165-216. 
Borensztein, E., and U. Panizza. 2009. “The Costs of Sovereign Default.” IMFStaffPapers 56 (4): 683-741.

Brooke, M., R. Mendes, A. Pienkowski, and E. Santor. 2013. “Sovereign Default and State-contingent Debt." Financial Stability Paper No. 27, Bank of England.

Buchheit, L. C. 2011. "Six Lessons from Prior Sovereign Debt Restructurings." Paper prepared for “Resolving the European Debt Crisis", a Conference Hosted by the Peterson Institute for International Economics and Bruegel. http://www.iie.com/publications/papers/buchheit20110913.pdf, Chantilly, France.

Buchheit, L. C., A. Gelpern, M. Culati, U. Panizza, B. W. di Mauro, and J. Zettelmeyer. 2013. “Revisiting Sovereign Bankruptcy.” Technical report, Committee on International Economic Policy and Reform, Brookings, Washington, DC.

Buiter, W. H., and A. Silbert. 1999. “UDROP: A Small Contribution to the International Financial Architecture.” Centre for Economic Performance, CEPDP 425, London School of Economics and Political Science, London, UK.

Calomiris, C., and R. J. Herring. 2013. "How to Design a Contingent Convertible Debt Requirement that helps Solve Our too-big-to-fail Problem." Journal of Applied Corporate Finance 25: 21-44.

Calomiris, C., and C. M. Kahn. 1991. "The Role of Demandable Debt in Structuring Optimal Banking Arrangements." The American Economic Review 81 (3): 497-513.

Chen, N., P. Classerman, B. Nouri, and M. Pelger. 2013. “Cocos, Bailin, and Tail Risk.” Working Paper No.0004, Office of Financial Research.

Conesa, J. C., and T. J. Kehoe. 2015. "Cambling for Redemption and Self-fulfilling Debt Crises." Research Department StaffReport 465, Federal Reserve Bank of Minneapolis.

Consiglio, A., and S. A. Zenios. 2016. "Risk Management Optimization for Sovereign Debt Restructuring." Journal ofClobalization and Development 6 (2): 181-214.

Consiglio, A., A. Carollo, and S. A. Zenios. 2016a. "A Parsimonious Model for Cenerating Arbitrage-free Scenario Trees." Quantitative Finance 16 (2): 201-212.

Consiglio, A., M. Tumminello, and S. A. Zenios. 2016b. “Pricing Sovereign Contingent Convertible Debt." Working Paper 16-05, The Wharton Financial Institutions Center, University of Pennsylvania, Philadelphia.

Culp, C. L. 2002. “Contingent Capital: Integrating Corporate Financing and Risk Management Decisions." Journal of Applied Corporate Finance 15 (1): 46-56.

Demertzis, M., and S. A. Zenios. 2018. "State Contingent Debt as Insurance for Euro-area Sovereigns.” Working Paper 3, Bruegel, Brussels, BE.

Flannery. M. J. 2005. “No Pain, No Gain: Effecting Market Discipline via 'Reverse Convertible Debentures', Chapter 3." In Capital adequacy beyond Basel. Banking, securities and insurance, edited by H. S. Scott, 29-70. Oxford: University Press.

Flannery, M. J. 2014. "Contingent Capital Instruments for Large Financial Institutions: A Review of the Literature." Annual Review of Financial Economics 6 (1): 225-240.

Froot, K. A., D. S. Scharfstein, and J. C. Stein. 1993. “Risk Management: Coordinating Corporate Investment and Financing Policies." The Journal of Finance 48 (5): 1629-1658.

GAMS Development Corporation. 2016. GAMS-A User's Guide. Published on line, Washington, DC. http://www.gams.com/help/topic/gams.doc/userguides/CAMSUsersGuide.pdf.

Celpern, A., B. Heller, and B. Setser. 2016. "Count the Limbs: Designing Robust Aggregation Clauses in Sovereign Bonds, chapter 6." In Too Little, Too Late. The Quest to Resolve Sovereign Debt Crises, edited by M. Guzman, J. A. Ocampo, and J. E. Stiglitz. Columbia University Press.

Gennaioli, N., A. Shleifer, and R. Vishny. 2012. Neglected Risks, Financial Innovation, and Financial Fragility. Journal of Financial Economics 104 (3): 452-468.

Classerman, P., and B. Nouri. 2016. “Market-triggered Changes in Capital Structure: Equilibrium Price Dynamics.” Econometrica 84 (6): $2113-$ 2153.

Guzman, M., and D. Lombardi. 2018. “Assessing the Appropriate Size of Relief in Sovereign Debt Restructuring." Research Paper 18-9, Columbia Business School, New York, NY.

Guzman, M., and J. E. Stiglitz. 2016. “Creating a Framework for Sovereign Debt Restructuring that Works, chapter 1." In Too Little, Too Late: The Quest to Resolve Sovereign Debt Crises, edited by M. Guzman, J. A. Ocampo, and J. E. Stiglitz, editors. New York, NY: Columbia University Press.

Hart, O., and L. Zingales. 2011. "A New Capital Regulation for Large Financial Institutions.” American Law and Economics Review13 (2): $453-490$. Himmelberg, C. P., and S. Tsyplakov. 2014. Incentive Effects and Pricing of Contingent Capital. Technical report, Coldman Sachs, New York, NY. Høyland, K., and S. W. Wallace. 2001. "Cenerating Scenario Trees for Multistage Decision Problems." Management Science 47 (2): $295-307$. IMF. 2017. "State-contingent Debt Instruments for Sovereigns." Staff report, International Monetary Fund.

Kamstra, M., and R. J. Shiller. 2009. "The Case for Trills: Giving The People and their Pension Funds a Stake in the Wealth of the Nation." Discussion Paper 1717, Cowles Foundation for Research in Economics, New Haven, CT: Yale University.

Klaassen, P. 2002. “Comment on 'Cenerating Scenario Trees for Multistage Decision Problems”. Management Science 48 (11): $1512-1516$.

Krugman, P. 1988. “Financing vs. Forgiving a Debt Overhang." Journal of Development Economics 29: 253-268.

McDonald, R. L. 2013. “Contingent Capital with a Dual Price Trigger.” Journal of Financial Stability 9 (2): 230-241.

Mody, A. 2013. "Sovereign Debt and Its Restructuring Framework in the Eurozone." Oxford Review of Economic Policy 29 (4): 715-744.

Neftci, N. S., and A. O. Santos. 2003. "Puttable and Extendible Bonds: Developing Interest Rate Derivatives for Emerging Markets." Working Paper WP/03/201, International Monetary Fund, Washington, DC.

O’Donoghue, B., M. Peacock, J. Lee, and L. Capriotti. 2014. "A Spread-return Mean-reverting Model for Credit Spread Dynamics." International Journal of Theoretical and Applied Finance, 17 (3): 1450017.

Panizza, U. 2013. “Do We Need a Mechanism for Solving Sovereign Debt Crises? A Rule-based Discussion.” Technical Report Working Paper No. 03/2013, Graduate Institute of International and Development Studies.

Pennacchi, C., and A. Tchistyi. 2016. “On Equilibrium when Contingent Capital has a Market Trigger: A Correction to Sundaresan and Wang, Journal of Finance (2015)." Technical report, Unpublished working paper.

Pisani-Ferry, J., A. Sapir, and C. B. Wolff. 2013. “EU-IMF Assistance to Euro-area Countries: An Early Assessment." Blueprint Series 10, Bruegel. Prescott, E. S. 2012. “Contingent Capital: The Trigger Problem.” Economic Quarterly 98 (1): 33-50. 
Reinhart, C., K. S. Rogoff, and M. A. Savastano. 2003. “Debt Intolerance.” NBER Working Paper 9908, National Bureau of Economic Research. Reinhart, C. M., and C. Trebesch. 2016. "Sovereign Debt Relief and Its Aftermath." Journal of the European Economic Association 14 (1): $215-251$.

Reinhart, C. M., and K. S. Rogoff. 2009. This Time Is Different: Eight Centuries of Financial Folly. Princeton, New Jersey: Princeton University Press. Reinhart, C. M., V. Reinhart, and K. S. Rogoff. 2015. “Dealing with Debt.” Journal of International Economics 96 (Supplement 1): S43-S55.

Rhodes, D., and D. Stelter. 2011. "Stop Kicking the Can Down the Road. The Price of Not Addressing the Root Causes of the Crisis." Technical report, The Boston Consulting Group.

Rockafellar, R. T., and S. Uryasev. 2000. “Optimization of Conditional Value-at-Risk.” Journal of Risk 2 (3): $21-41$.

Schumacher, ]., C. Trebesch, and H. Enderlein. 2018. "Sovereign Defaults in Court." Working Paper No. 2135, European Central Bank.

Sturzenegger, F., and J. Zettelmeyer. 2006. Debt Defaults and Lessons from a Decade of Crises. Cambridge, MA: MIT Press.

Sundaresan, S., and Z. Wang. 2015. “On the Design of Contingent Capital with a Market Trigger.” The Journal of Finance 70 (2): 881-920.

Trebesch, C. 2011. “Sovereign Debt Restructurings 1950-2010: A New Database." Unpublished paper, available at: sites.google.com/site/christophtrebesch/data, University of Munich, Munich, Gemany.

Weber, A. A., J. Ulbrich, and K. Wendorff. 2011. Safeguarding Financial Market Stability, Strengthening Investor Responsibility, Protecting Taxpayers. Frankfurt Allgemeine Zeitung.

Zenios, S. A. 2007. Practical Financial Optimization. Decision Making for Financial Engineers. Malden, MA: Blackwell-Wiley Finance.

Zenios, S. A. 2016. "Fairness and Reflexivity in the Cyprus Bail-in." Empirica 43 (3): 579-606.

Zenios, S. A., and W. T. Ziemba, editors. 2007. Handbook of Asset and Liability Management. Vol. 1. Theory and Methodology and Vol. 2 Applications and Case Studies. North-Holland, The Netherlands: Handbooks in Finance.

Zettelmeyer, J., C. Trebesch, and M. Culati. 2013. “The Greek Debt Restructuring: An Autopsy.” Economic Policy 28 (75): 513-563. 